\title{
Systems-level analysis of monocyte responses in inflammatory bowel disease identifies IL-10 and IL-1 cytokine networks that regulate IL-23
}

Dominik Aschenbrenner $^{1 *}$, Maria Quaranta ${ }^{1,8 *}$, Soumya Banerjee ${ }^{1,2}$, Nicholas Ilott ${ }^{2}$, Joanneke Jansen ${ }^{1,7}$, Boyd A. Steere ${ }^{3}$, Yin-Huai Chen ${ }^{1}$, Stephen $\mathrm{Ho}^{3}$, Karen Cox ${ }^{3}$, Oxford IBD Cohort Investigators ${ }^{1}$, Carolina V. Arancibia-Cárcamo ${ }^{1}$, Mark Coles ${ }^{2}$, Eamonn Gaffney ${ }^{7}$, Simon Travis ${ }^{1}$, Lee A. Denson ${ }^{4}$, Subra Kugathasan ${ }^{5}$, Jochen Schmitz ${ }^{3}$, Fiona Powrie ${ }^{2}$, Stephen Sansom $^{2 *}$, and Holm H. Uhlig ${ }^{1,6} *$

\section{Author affiliations:}

${ }^{1}$ Translational Gastroenterology Unit, NIHR Oxford Biomedical Research Centre, John Radcliffe Hospital, University of Oxford, Oxford, UK.

${ }^{2}$ Kennedy Institute of Rheumatology, University of Oxford, Oxford, UK.

${ }^{3}$ Immunology Translational Sciences; Lilly Research Laboratories. Eli Lilly and Company

Lilly Corporate Center, Indianapolis IN 46285, USA.

${ }^{4}$ Division of Pediatric Gastroenterology, Hepatology and Nutrition, Cincinnati Children's Hospital Medical Center, Cincinnati, Ohio, USA.

${ }^{5}$ Division of Pediatric Gastroenterology, Emory University School of Medicine, Atlanta, Georgia, USA.

${ }^{6}$ Department of Paediatrics, University of Oxford, Oxford, UK.

${ }^{7}$ Wolfson Centre for Mathematical Biology, University of Oxford, Oxford, UK.

${ }^{8}$ Current address: Division of Gastroenterology, Humanitas Clinical and Research Center, Rozzano, Milan, Italy.

*These authors contributed equally to this work

\section{Corresponding author:}

Holm H. Uhlig (holm.uhlig@ndm.ox.ac.uk), Translational Gastroenterology Unit, Experimental Medicine, University of Oxford, John Radcliffe Hospital Oxford, OX3 9DU, UK. Phone: 00441865857963

\section{Conflict of Interest Statement:}

This research was funded by the National Institute for Health Research (NIHR) Oxford Biomedical Research Centre (BRC). The views expressed are those of the author(s) and not 
necessarily those of the NHS, the NIHR or the Department of Health. The study has been supported via a collaborative grant by Eli Lilly. BAS, SH, KC and JS are current or previous employees of Eli Lilly. HHU received research support or consultancy fees from UCB Pharma, Eli Lilly, Boehringer Ingelheim, Pfizer and AbVie. FP has received research support or consultancy fees from GSK, UCB Pharma, Medimmune, Janssen and Eli Lilly. SPLT has been adviser to, in receipt of educational or research grants from, or invited lecturer for AbbVie; Amgen; Asahi; Biogen; Boehringer Ingelheim; BMS; Cosmo; Elan; Enterome; Ferring; FPRT Bio; Genentech/Roche; Genzyme; Glenmark; GW Pharmaceuticals; Janssen; Johnson \& Johnson; Eli Lilly; Merck; Novartis; Novo Nordisk; Ocera; Pfizer; Shire; Santarus; SigmoidPharma; Synthon; Takeda; Tillotts; Topivert; Trino Therapeutics with Wellcome Trust; UCB Pharma; Vertex; VHsquared; Vifor; Warner Chilcott and Zeria. SK has received consultancy fees from Janssen and Takeda.

\section{Author contributions:}

DA, MQ performed experiments. SNS, SB, DA, NI, BAS, and JJ performed bioinformatics analyses. SNS was responsible for the scRNA-seq, WGCNA and signature deconvolution analyses. JJ, MC and EG were responsible for the mathematical modelling. CVA-C, ST, HHU, TD and SK contributed patient cohort recruitment and analysis. JS, ST, SK, FP, SNS and HHU supervised the study. All authors discussed data and contributed to the manuscript.

\section{Keywords:}

Cytokines, Inflammatory Bowel Disease, Monocytes, Personalized Medicine

\section{Abbreviations:}

BH, Benjamini \& Hochberg; CD, Crohn's disease; CD, Cluster of differentiation; FACS, Fluorescence assisted cell sorting; GFP, Green fluorescent protein; IBD, Inflammatory bowel disease; IBDu, IBD unclassified; IL, Interleukin; LPS, Lipopolysaccharide; MACS, Magnetassisted cell sorting; MDP, Muramyl-dipeptide; OSM, Oncostatin M; PBMC, Peripheral blood mononuclear cells; single cell RNA-sequencing (scRNA-seq); STAT, Signal transducer and activator of transcription; Th, T helper; TNF, Tumour necrosis factor; UC, Ulcerative colitis. 


\section{Data availability:}

The data supporting the findings described in this study are available from the corresponding author upon request. Single cell RNA sequencing data generated in this study have been deposited at NCBI's Gene Expression Omnibus (GEO) and are accessible under GEO Series accession number GSE130070. Microarray data generated in this study have been deposited at NCBI's Gene Expression Omnibus and are accessible under GEO Series accession number GSE137680. Both data sets are available via a GEO SuperSeries that represents the publication as a whole (GSE138009).

\section{Acknowledgments:}

We thank all patients, volunteers and blood donors for participation in this study. We thank Priya Siddhanathi, James Chivenga, Jennifer Hollis and Sebastian Rogatti Granados for excellent technical assistance, Helen Ferry for flow cytometry support. We thank the Oxford Genomics Centre Single-cell core unit for their technical assistance and support. We like to thank Jon Sedgwick for discussion.

We acknowledge the contribution of the BRC Gastrointestinal biobank (11/YH/0020, 16/YH/0247), which is supported by the National Institute for Health Research (NIHR) Oxford Biomedical Research Centre (BRC). We acknowledge support of the BRC (FP, ST, HHU), the Leona M. and Harry B. Helmsley Charitable Trust (FP, HHU), research grants from the Crohn's \& Colitis Foundation of America (LAD, SK, HHU, FP and SP), the COLORS in IBD project via a ESPGHAN network grant (HHU), the Wellcome Trust (FP), the Kennedy Trust for Rheumatology Research (SNS), and to the individual study institutions participating in the RISK study. We thank the Oxford IBD Cohort Investigators** Adam Bailey, Ellie Barnes, Elizabeth Bird-Lieberman, Oliver Brain, Barbara Braden, Jane Collier, James East, Alessandra Geremia, Lucy Howarth, Satish Keshav, Paul Klenerman, Simon Leedham, Rebecca Palmer, Astor Rodrigues, Alison Simmons, Peter Sullivan. The views expressed are those of the author(s) and not necessarily those of the NHS, the NIHR or the Department of Health. 


\begin{abstract}
BACKGROUND \& AIMS:

Dysregulated immune responses are the cause of inflammatory bowel diseases. Studies in both mice and humans suggest a central role of IL-23 producing mononuclear phagocytes in disease pathogenesis. Mechanistic insights into the regulation of IL-23 are prerequisite for select IL-23 targeting therapies as part of personalized medicine.

METHODS:
\end{abstract}

We performed transcriptomic analysis to investigate IL-23 expression in human mononuclear phagocytes and peripheral blood mononuclear cells. We investigated the regulation of IL-23 expression and used single-cell RNA-sequencing to derive a transcriptomic signature of hyper-inflammatory monocytes. Using gene network correlation analysis, we deconvolve this signature into components associated with homeostasis and inflammation in patient biopsy samples.

RESULTS:

We characterized monocyte subsets of healthy individuals and patients with inflammatory bowel disease that express IL-23. We identified auto- and paracrine sensing of IL-1 $\alpha /$ IL-1 $\beta$ and IL-10 as key cytokines that control IL-23-producing monocytes. Whereas Mendelian genetic defects in IL-10 receptor signalling induced IL-23 secretion, uptake of whole bacteria induced IL-23 production via acquired IL-10 signalling resistance. We found a transcriptional signature of IL-23-producing inflammatory monocytes that predicted both disease and resistance to anti-TNF therapy and differentiated that from an IL-23-associated lymphocyte differentiation signature that was present in homeostasis and in disease.

CONCLUSION:

Our work identifies IL-10 and IL-1 as critical regulators of monocyte IL-23 production. We differentiate homeostatic IL-23 production from hyper-inflammation-associated IL-23 production in patients with severe ulcerating active Crohn's disease and anti-TNF treatment non-responsiveness. Altogether, we identify subgroups of patients with inflammatory bowel disease that might benefit from IL-23p19 and/or IL-1 $\alpha /$ IL-1 $\beta$-targeting therapies upstream of IL-23. 


\section{INTRODUCTION}

The pathogenesis of inflammatory bowel disease (IBD), that include Crohn's disease (CD) and ulcerative colitis (UC) and IBD unclassified (IBDu) is caused by dysregulated innate and adaptive immune responses that drive chronic relapsing tissue inflammation ${ }^{1}$. Genetic studies suggest a complex polygenic inheritance driven by defective innate and adaptive immunity $^{1,2}$. IL-23 signalling and T-helper (Th)1/Th17 immunity are significant mediators of intestinal inflammation as indicated by genetic variants in $I L 23 R$ encoding the IL-23 receptor ${ }^{3}$ as well as RORC, STAT3, IRF5, IL1R1, IL6ST, IL12B, TYK2, IL21, JAK2, IFNG, SMAD3 and $C C R 6^{4,5}$.

Monocytes, macrophages and dendritic cells produce IL-23 in response to bacteria- and fungi-derived microbial stimuli and drive Th1 and Th17 differentiation in the pathogenesis of intestinal inflammation $^{6-9}$. In addition to a role of pro-inflammatory and anti-inflammatory cytokine networks ${ }^{10}$, mouse models as well as human Mendelian disorders highlight the essential role of IL-10 signalling in controlling inflammatory cytokine responses. Therapeutic approaches that target the pro-inflammatory arm of the immune system by blocking cytokine signalling or by affecting intestinal cell migration are effective in subgroups of patients with $\mathrm{IBD}^{8}$. Mice that lack IL-23p19 are protected from developing colitis in innate as well as lymphocyte replete models of intestinal inflammation induced by IL-10 signalling defects, bacterial colonisation or innate immune stimulation via the anti-CD40 ${ }^{7}, 11$. Blockade of IL23 p19 and IL-12p40 showed therapeutic benefit for patients with $\mathrm{CD}$ and $\mathrm{UC}^{12,13}$.

To predict genetic susceptibility or disease course, individual loci and genetic risk scores $^{14,15}$ as well as gene expression signatures or transcriptomic scores of peripheral CD8 ${ }^{+}$ $\mathrm{T}_{\text {cells }}{ }^{16}$, peripheral blood ${ }^{17}$ or intestinal tissue ${ }^{18}$ are emerging patient stratification strategies in IBD. Membrane-bound TNF ${ }^{19}$ and IL-6/Oncostatin M (OSM) associated cytokines ${ }^{18}$ predict anti-TNF non-response. However, transcriptional signatures that implement IL-23 expression have not been described.

Personalised medicine targeting the IL-23 axis requires an understanding of the cellular sources, networks and regulation of IL-23. Here we investigate the regulation of IL-23, describe distinct monocyte subsets that express IL-23 and identify IL-1-signalling as the key cytokine for the differentiation IL-23-producing monocytes. We identify a hyper inflammatory signature of IL-23-producing monocytes in intestinal tissue transcriptomes of patients with IBD and find an additional signature of IL-23 that is associated with lymphocyte cell differentiation in healthy tissue. 


\section{MATERIALS AND METHODS}

\section{Human samples, cell isolation and cell culture:}

Patients with IBD and controls were recruited via the Oxford IBD cohort and Gastrointestinal biobank (REC 11/YH/0020 and 16/YH/0247). All patients with IBD and healthy volunteers provided written informed consent. Peripheral blood mononuclear cells (PBMC) were purified using Ficoll-Paque density gradient purification. For stimulation assays, $0.5 \times 10^{6}-1 \times 10^{6} \mathrm{PBMC}$ or MACS-purified CD14 ${ }^{+}$monocytes (Mitenyi Biotec) were cultured in $200 \mu 1$ medium in duplicates in round bottom 96-well plates. For detailed description of cell culture and stimulation, including whole bacteria preparation for stimulation, see Supplementary Experimental Procedures.

\section{Flow cytometry:}

We applied surface immunostaining for identification of immune cell subsets in complex mixtures of cells such as PBMC or enriched CD14 $4^{+}$monocytes. Surface staining and intracellular cytokine staining were combined for the analysis of frequencies of cytokine producing cells following stimulation and for the validation of single cell RNA-sequencingidentified monocyte clusters. Intracellular staining for phosphorylated STAT3 was used to analyse IL-10-responsiveness in $\mathrm{CD}_{1} 4^{+}$monocytes. For detailed description of experimental procedures (surface staining, intracellular cytokine staining, phosphoflow) stimulation conditions, reagents, antibodies and mathematical modelling of cytokine interactions please see Supplementary Experimental Procedures.

\section{Protein level analysis:}

Cytokine levels in cell culture supernatants were assayed using the Milliplex human cytokine/chemokine magnetic bead 41-plex panel (Milliplex Billerica, MA, USA; HCYTOMAG-60K-PX41) and acquired on a Luminex LX200 flow reader. For detailed description of experimental procedures please see Supplementary Experimental Procedures.

\section{ELISpot:}

A dualcolor ELISpot assay was developed for the detection of IL-10 and IL-23 producing cells. Please see Supplementary Experimental Procedures for detailed description of protocol and reagents. 
Single cell RNA-sequencing of monocytes, identification and characterisation of gene co-expression modules in the RISK cohort and Identification and characterisation of an IL-10-responsive monocyte gene signature:

For a detailed description of cell isolation, stimulation, preparation of cells and single cell RNA-sequencing, data analysis including cross-condition analysis of single-cell RNAsequencing data and comparison of LPS + anti-IL-10R single-cell RNA-sequencing data please see Supplementary Experimental Procedures.

\section{Patient cohorts and bioinformatics analysis:}

Cohorts of patients with IBD analysed in this study include the RISK study ${ }^{20,21}$ GEO (GSE57945), Affymetrix microarray data from Janssen ${ }^{22}$ (GSE12251) and mucosal gene expression data by I. Arijs et. al. ${ }^{23}$ (GSE16879). For details regarding the analysis and data processing for the identification and characterisation of gene co-expression modules in the RISK cohort, identification and characterisation of an IL-10-responsive monocyte gene signature and validation see Supplementary Experimental Procedures.

\section{Gene expression analysis using real time PCR and expression array:}

Total RNA was extracted from cultured cells using the RNeasy Plus Mini Kit (Qiagen). The RNA yield was determined via Nanodrop ND1000 UV-vis Spectrophotometer. Complementary DNA (cDNA) was synthesized from $200 \mathrm{ng}$ of total RNA and transcribed using the High Capacity cDNA Reverse Transcription Amplification Kit (Applied Biosystems). Real-time PCRs were performed in 96-well plates using the PrecisionPLUS qPCR Mater Mix (Primer Design) and the CFX96 Touch Real-Time PCR Detection System (BIO-RAD). The Affymetrix Human Transcriptome Array 2.0 (HTA2) was used for expression array analysis. For detailed description of methods, reagents and statistical analysis please see Supplementary Experimental Procedures.

\section{Statistical analysis}

Statistical analyses were performed with GraphPad Prism, version 8.0 for Macintosh (GraphPad Software, La Jolla, CA) or Microsoft Excel for Mac, version 15.32. P-values $\leq 0.05$ were considered significant and indicated as follows: $* \mathrm{P} \leq 0.05 ; * * \mathrm{P} \leq 0.01$; *** $\mathrm{P} \leq 0.001$; $* * * * \mathrm{P} \leq 0.0001$. Statistical tests are described in figure legends. 


\section{RESULTS}

IL-10 signalling blockade facilitates IL-23 production by a subset of peripheral

\section{blood monocytes}

We investigated the regulation of IL23A expression by subjecting PBMC from 41 patients with IBD (Supplementary Fig. 1A; Supplementary Table 1) to IBD-relevant stimuli that target different aspects of innate and adaptive immune cell responses. Lipopolysaccharide (LPS), muramyl-dipeptide (MDP), T cell receptor and co-stimulation $(\alpha \mathrm{CD} 3 / \alpha \mathrm{CD} 28$ coated beads) and IL-10 signalling blockade were used alone or in combination based on the concept that innate pathogen recognition receptor responses (in particular NOD2 ${ }^{14}$ and TLR4 ${ }^{24}$ ), $\mathrm{T}$ cell responses and IL-10 signalling defects are implicated by multiple genetic IBD susceptibility loci and Mendelian forms of $\mathrm{IBD}^{25}$. We performed microarray gene expression analysis of all conditions at 16 hours following stimulation in presence or absence of IL-10 receptor (IL-10R) blocking antibodies. We identified stimulus-specific and shared gene expression signatures (Supplementary Fig. 1B and 1C; Supplementary Table 2). LPS, L18MDP, and $\alpha \mathrm{CD} 3 / \alpha C D 28$ coated beads induced 319,187 and 312 genes respectively out of which 109, 19, and 175 were condition-specific genes (BH adjusted $\mathrm{p}<0.05$, $|\mathrm{fc}| \geq 1.5$; Supplementary Fig. 1B). Changes in $I L 23 \mathrm{~A}$ expression were moderate under these conditions (Supplementary Fig. 1C). We next investigated the role of IL-10 signalling during LPS, L18MDP, and $\alpha \mathrm{CD} 3 / \alpha \mathrm{CD} 28$ stimulation. In total 36 genes were up- and 29 genes down-regulated by IL-10 blockade, with most of the changes being found during LPS stimulation $(|\mathrm{fc}|>1.5$, BH-adjusted $\mathrm{p}<0.05$; Supplementary Fig. 1D and 1E; Supplementary Table 3). IL23A expression was significantly up-regulated under conditions of LPS or L18MDP stimulation and IL-10 signalling blockade (Supplementary Fig. 1C and 1D).

To investigate the regulation of secreted proteins by IL-10, we analysed cell culture supernatants after 16 hours stimulation (Figure 1A). LPS stimulation significantly upregulated protein secretion in 17 among the 40 proteins tested $(|\mathrm{fc}| \geq 4$-fold, BH Adjusted $\mathrm{p}<0.05)$. The addition of IL-10 blockade significantly up-regulated 6 of the LPS-induced factors (IL-23p19, GM-CSF, IL-1 $\alpha$, IL-12p70, IL-12p40 and IFN- $\gamma$ ) (BH Adjusted $\mathrm{p}<0.05,|\mathrm{fc}| \geq 4$-fold) (Figure 1A). Compared to control, LPS stimulation resulted in a mean 85.23-fold induction (mean concentration control: $3.30 \mathrm{pg} / \mathrm{ml}$, mean concentration LPS $135.98 \mathrm{pg} / \mathrm{ml}$ ) of IL-23 (BH adjusted $\mathrm{p}<0.05$ ) while combined LPS and anti-IL-10R treatment induced a mean 2,544.95fold increased (mean concentration LPS and anti-IL-10R $4737.57 \mathrm{pg} / \mathrm{ml}$ ) IL-23 secretion (BH adjusted $\mathrm{p}<0.05$ ) (Figure 1B). 
We next sought to understand the kinetics and cellular sources of IL-10 regulated LPSresponsive cytokines within the complex PBMC mixture. We quantitated IL-1 $\alpha$, IL-1 $\beta$, IL-4, IL-6, IL-10, IL-12p40, IL-13, IL-17A, IL-23p19, GM-CSF, IFN- $\gamma$ and TNF production in monocytes, $\mathrm{NK}$ cells, $\mathrm{CD} 4^{+} \mathrm{T}$ cells and $\mathrm{CD} 8^{+} \mathrm{T}$ cells by intracellular flow cytometry in patients with IBD and healthy donors (HD) PBMCs (Supplementary Fig. 2A and 2B). To capture the early and late phase of cytokine production we analysed cells at 6 and 16 hours following stimulation. At both time points of stimulation, $\mathrm{CD} 14^{+}$monocytes were the major source of IL-10, IL-1 $\alpha$, IL-1 $\beta$, IL-6 and TNF (Supplementary Fig. 2A and 2B). CD4 ${ }^{+} \mathrm{T}$ cells contributed to the early cytokine response via expression of IFN- $\gamma$, IL-17A, GM-CSF and TNF, while $\mathrm{CD}^{+} \mathrm{T}$ cells produced IFN- $\gamma$ and TNF (Supplementary Fig. 2A and 2B). NK cells contributed to the cytokine response by production of IFN- $\gamma$ and TNF only at the late time point. At 16 hours stimulation monocytes still produced IL- $1 \alpha$ and IL-1 $\beta$ while IL-6, TNF and IL-10 expression were reduced. All these cytokines were increased when cells were stimulated with LPS and anti-IL-10R. IL-23 (IL-12p40 IL-23p19 ${ }^{+}$) and IL-12 (IL-12p40 ${ }^{+}$IL-23p19-) expression were selectively increased in $\mathrm{CD}_{1} 4^{+}$relative to $\mathrm{CD} 14^{-}$leukocytes after IL-10 receptor blockade (Figure 1D, 1E and 1F). These results were confirmed in PBMC obtained from HDs (Supplementary Fig. 2C, 2D and 2E).

Together, these results demonstrate that IL-10 signalling regulates IL-23 (IL-12p40 IL$\left.23 \mathrm{p} 19^{+}\right)$production in a subset of CD $14^{+}$monocytes (IBD mean $=3.03 \%(95 \% \mathrm{CI}$ of the mean: lower $=1.11$, upper $=4.96)$; HD mean $=5.32 \%(95 \%$ CI of the mean: lower $=3.51$, upper $=$ 7.14)).

Single cell sequencing identifies inflammatory $I L-10$ regulated monocyte phenotypes

FACS analysis suggested the presence of unknown functional heterogeneity within the population of stimulated $\mathrm{CD} 14^{+}$monocytes (see e.g. Figure 1D). To characterise the LPSinduced and IL-10-regulated transcriptional profile of monocytes subsets, and to differentiate population-wide transcriptional changes from subset-specific responses we performed single cell RNA-sequencing (scRNA-seq) of unstimulated, LPS-stimulated and LPS and anti-IL-10Rtreated CD14 ${ }^{+}$MACS-sorted monocytes from HDs (Figure 2A). Among the 8 clusters of monocytes that were detected, 2 clusters emerged after LPS stimulation and 3 additional clusters largely comprised of LPS and anti-IL-10R stimulated cells (Figure 2A and 2B). 
The eight clusters showed discrete gene expression (Figure 2C) and were enriched for biological processes suggestive of different functional specialisations (Supplementary Fig. 3A). The majority of unstimulated monocytes were lysozyme ${ }^{+}\left(\right.$LYZ), CD52 ${ }^{+}$(CAMPATH1), and $\mathrm{FCNI}^{+}$expressing $\mathrm{CD} 14^{\text {high }}$ monocytes (cluster 0 - unstimulated, classical monocytes), while a minority of unstimulated monocytes displayed a $C D 52^{+}, \mathrm{FCN1}^{+}, \mathrm{CD} 16^{+}(\mathrm{FCGR} 3 \mathrm{~A})$ $C D 14^{\text {low }}$ phenotype (cluster 7 - unstimulated, non-classical monocytes). Two clusters of cells that emerged following LPS stimulation were comprised of $I L 1 B^{+}$cells. The first showed expression of CD14 and was enriched for genes associated with "T cell tolerance induction" (cluster 1 - LPS-stimulated), while the second displayed high CD300E and CD163 expression and an enrichment for "monocyte activation" genes (cluster 2 - LPS-stimulated). The three additional monocyte phenotypes that appeared upon combined LPS stimulation and IL-10R blockade were demarcated by (i) high expression of type 1 interferon responsive genes (e.g. IFIs, IFITs, ISGs, OASs, IRFs) and genes linked to antigen processing and presentation (e.g. $B 2 M, C C R 7, H L A, C D 74)$ (cluster 3 - LPS and anti-IL-10R, called IFN-induced monocytes); (ii) high expression of ITGAX and enrichment for genes associated with "superoxide generation" and "positive regulation of neutrophil activation" (cluster 6 - LPS and anti-IL$10 \mathrm{R}$, called microbicidal monocytes) and (iii) expression of pro-inflammatory genes including (IL1B, IL6, IL23A, CCL20 and PTGS2) and enrichment of genes associated with "Th17 cell lineage commitment", "positive regulation of acute inflammatory response" and "interferon gamma production" (cluster 4 - LPS and anti-IL-10R; called IL-23 ${ }^{+}$inflammatory monocytes). These three phenotypes in LPS-stimulated anti-IL-10R-treated monocytes were replicated in a second donor (Supplementary Fig. 3B).

Interestingly, while $I L 23 A$ and $I L I R I$ were expressed in a cluster-specific manner under the "hyper-inflammatory" LPS and anti-IL-10R condition, IL10, IL10RA and IL10RB as well as $I L 1 A / I L I B$ mRNA showed broader, cross-condition and cross-cluster expression (Figure 2D).

IL-10-producing monocytes control IL-23-producing monocytes through paracrine signalling

In PBMC we observed that $I L 23 A$ and $I L 10$ mRNA expression were strongly correlated (Spearmans' $\mathrm{r}=0.84, \mathrm{p}<0.0001$ ) when stimulated with LPS and IL-10R blockade. (Supplementary Fig 4A). These data indicate that IL10 mRNA expression itself is tightly regulated by IL-10 signalling as part of a negative feedback mechanism. We assumed that 
$I L 23 \mathrm{~A}$ and $I L 10$ would be produced by the same cells. However, inspection of the single-cell data suggested that this might not be the case and intracellular flow cytometry demonstrated that monocytes expressed IL-10 prior to up-regulating IL-23 (Supplementary Fig. 2A and 2B and Supplementary Fig. 4B) and that IL-10 and IL-23 largely originate from distinct cells (Figure 3A). This indicated that IL-10 may regulate IL-23 production through a paracrine mechanism in functionally distinct cells. Alternatively, IL10 and IL23A mRNA expression might occur sequentially (i.e. early IL-10 producer become IL-23 producer) or an oscillatory fashion within individual cells.

To distinguish between these possibilities, we performed a dual-colour ELISpot using MACS-purified monocytes. In line with a paracrine model where IL-10 producing monocytes regulate IL-23 production in others, we found that IL-10-producing monocytes were distinct from IL-23-producing monocytes and that double-stained cells were a minority (Figure 3B and 3C). These results suggest that IL-10 producing monocytes regulate IL-23 producing cells and demonstrate that the development of IL-23-producing monocytes is not a consequence of local cytokine segregation in tissue culture.

\section{Deconvolution of intestinal IL-23 gene expression in intestinal tissue}

We next sought to understand the context of IL-23 expression during intestinal inflammation. We compared expression of IL-23 in ileal biopsies from CD patients and noninflamed controls (HD or UC) in samples from the paediatric RISK cohort $^{20}$ (Figure 4A). As expected, $I L 23 A$ and $I L 12 B$ were expressed in the CD patient samples along with $I L 1 A, I L 1 B$ and $I L 6$. However, we also found $I L 23 A$ and $I L 12 B$ expression in non-inflamed control biopsies (Figure 4A and 4B) where $I L 23 A$ expression was associated with $T N F$ rather than $I L 1 B$ expression (Figure 4C and 4D). We therefore performed weighted gene co-expression network analysis (WGCNA) ${ }^{26}$ to investigate the possible sources and roles of IL23A in the inflamed and non-inflamed intestine (Supplementary Fig. 5A). This analysis identified 22 modules of co-expressed genes that were named according to their gene members and enrichments for biological pathways and sets of cell type marker genes (Supplementary Table 4). Clustering of the modules by their expression patterns in the RISK cohort patients identified six major groups that could be broadly distinguished by their correlations with diagnosis of CD, IL23A expression, epithelial gene expression, mitochondrial activity and cell growth genes. (Supplementary Fig. 5A, Supplementary Fig. 5B). 
Most prominently, we found an "inflammatory cytokine" module that was significantly correlated with both CD ("crohns", r=0.55) and IL23A expression (r=0.35) (Supplementary Fig. 5B). This module contained key myeloid and stromal markers genes (CD14, PDPN), proinflammatory cytokines (including $O S M, I L 1 B$ and IL6) and Fibroblast activation protein $(F A P)$ (Supplementary Fig. 5B) in keeping with the emerging concept of a pathogenic myeloid-stromal cell circuit in $\mathrm{IBD}^{18,24}$. Intriguingly, however, we found that $I L 23 \mathrm{~A}$ expression was most strongly correlated with two modules of "immune cell differentiation" ( $\mathrm{r}=0.7)$ and "lymphocyte differentiation" ( $r=0.71)$ genes (Supplementary Fig. 5A). Of these, the "immune cell differentiation" module was weakly correlated with $\mathrm{CD}(\mathrm{r}=0.2)$, associated with expression of myeloid (CD14) and lymphoid $(C D 79 A, C D 4)$ cell markers and enriched for "myeloid dendritic cell differentiation" (Supplementary Fig. 5B and 6A). The "lymphocyte differentiation" module showed an expression signature suggestive of lymphoid follicles including individual markers of $\mathrm{B}$ and $\mathrm{T}$-cell identity $(C D 79 A, C D 4)$ and differentiation $(B A C H 2)^{25,26}$ (Supplementary Fig. 5B) as well as enrichments for gene ontology categories related to lymphoid cell differentiation, proliferation and selection (Supplementary Fig. 6A). While the "lymphocyte differentiation" module was not correlated with CD it was unique in showing significant enrichments for two sets of IBD GWAS associated genes (odds ratios > 3), suggesting that this set of genes is relevant for the pathogenesis of IBD (Supplementary Fig. 6B). We also noted that both of the IL23A-associated "immune cell differentiation" and "lymphocyte differentiation" modules were significantly enriched for genes belonging to the KEGG “Th17 cell differentiation” pathway (Supplementary Fig 6A).

Overall, the network analysis suggested that $I L-23$ expression was primarily associated with lymphoid cell differentiation in both health and disease. We therefore sought to understand which of the IL-10 regulated monocyte genes were specific to disease-associated inflammation. We correlated the expression of a curated set of IL-10 regulated monocyte genes (35 genes specific to combined LPS and anti-IL-10R stimulation scRNA-seq; Figure 4E and 4F; Supplementary methods section "Identification and characterisation of an IL-10responsive monocyte gene signature") with the eigengenes for the CD-associated "inflammatory cytokine" and the non-inflammatory "lymphocyte differentiation" modules in the RISK cohort data. This analysis identified three subsets of IL-10 regulated monocyte genes (Figure 4E). These comprised of (i) genes correlated only with the $\mathrm{CD}$ associated "inflammatory cytokine" module (black box, Figure 4E), (ii) a set of genes correlated with both the "inflammatory cytokine" and "lymphocyte differentiation" modules (grey box, Figure $\mathbf{4 E}$ ), and (iii) genes correlated with only the non-inflammatory "lymphocyte differentiation" 
module (green box, Figure 4E). The IL-10-regulated genes that correlated with the "inflammatory cytokine" but not the "lymphocyte differentiation" eigengene (black box, Figure 4E) showed a significantly superior ability to predict anti-TNF response after 4 to 6 weeks treatment in an independent cohort of patients with UC (UC-cohort GSE12251) ${ }^{22}$ and diagnosis of CD in the RISK cohort ${ }^{20}$ (Figure 4F, 4G and 4H, Supplementary Table 5). By contrast, IL-10-regulated monocyte genes that correlated with "lymphocyte differentiation" but not "inflammatory cytokines", had poorer predictive ability (Figure 4F, 4G and 4H). To validate our findings, we analysed intestinal transcriptome data of an additional adult cohort of patients with CD and UC (GSE16879) ${ }^{22}$. Similar to our initial results, inflammatory monocytes genes expression predicted disease activity and anti-TNF non-response in adult CD patients ileal biopsies transcriptomes. In colonic biopsies these genes were not predictive of disease activity but distinguished patients with CD or UC anti-TNF non-response (Supplementary Fig. 7A and 7B).

These data therefore identify a subset of IL-10 regulated monocyte-derived genes, including CXCL1/2, IL1A, IL1B, INHA, IL6, CCL3/4, PTGS2, CSF2/3 and GBP1 that show a specific association for disease-associated intestinal inflammation in the RISK and GSE16879 CD cohort. By contrast, cytokines such as IL-23 and TNF were not specific for disease suggestive of context-dependent roles in homeostasis and inflammation.

\section{Monocyte uptake of whole bacteria causes IL-10 resistance and IL-23 secretion}

The analysis of gene expression data in the RISK cohort suggests IL-23 expression despite presence of IL-10 in a subset of patients with macroscopic inflammation and deep ulcerating IBD in the absence of Mendelian IL-10 or IL-10R loss of function DNA variants, i.e. functional IL-10 resistance. In light of the epithelial barrier defect in ulcerating disease that predisposes to bacterial translocation, we tested whether direct contact of monocytes with bacteria can induce functional IL-10 resistance. We treated monocytes for 16 hours with-heat killed Salmonella typhimurium or Escherichia coli strain Nissle. Interestingly, monocytes produced IL-23 and IL-10 upon stimulation (Figure 5A and 5B) reminiscent of LPS stimulation in presence of IL-10R blockade. The cellular dichotomy of IL-23 and IL-10 production was maintained under these conditions (Figure 5B). To assess IL-10 responsiveness in previously stimulated monocytes we extensively washed cell cultures, subsequently exposed those to recombinant human IL-10 and evaluated phosphorylation of signal transducer and activator of transcription (STAT) 3 (Figure 5C). Indeed, bacterial 
stimulation was associated with an increased proportion of cells that did not respond to IL-10 demonstrating that monocyte encounter of whole bacteria induces a state of IL-10 resistance. (Figure 5D and 5E).

\section{$I L-1 \alpha$ and $I L-1 \beta$ are essential for monocyte $I L-23$ production}

The regulation of monocyte-derived IL-23 and IL-10 suggested co-regulation via additional factors (likely cytokines). We therefore investigated the functional effects of 11 coregulated cytokines on monocyte IL-23 production (Figure 6A and 6B, Supplementary Fig. 8A and 8B). Strikingly, when blocking IL-1R1, IL-23 production was near completely abolished (Figure 6A and 6B, Supplementary Fig. 8A - C). Blocking IL-1 $\beta$ or IL-1 $\alpha$ alone had only partial or no effect on IL-23 production indicating that either cytokine can compensate for the absence of the other in driving monocyte IL-23 production (Figure 6A, Supplementary Fig. 8A). The effect of IL-1 $\beta$ on IL-23 expression was context specific, since addition of IL$1 \beta$ in the presence of anti-IL-10R blockade alone did not induce IL-23 expression (Supplementary Fig. 8D). None of the other tested cytokines (GM-CSF, IL-6, IL-11, IL-17A, IL-18, IL-19, IL-23, IL-24, IL-36 $\gamma$, TNF and Type I Interferon) demonstrated a significant impact on IL-23 production. Although not essential, addition of IFN- $\gamma$ or IL-12 increased monocyte IL-23 production (Figure 6A and 6B, Supplementary Fig. 8A and 8B).

To investigate the effects of IL-1R1 blockade on functional monocyte clusters, we stimulated PBMC from HDs with combinations of LPS and anti-IL-10R and analysed monocyte metaclusters-associated protein expression. In line with the single cell mRNA sequencing experiments the predicted clusters associated with LPS and combined LPS and anti-IL-10R stimulation (Figure 6C, gating strategy outlined in Supplementary Fig. 8E). Blockade of IL-1R1 specifically inhibited the development of IL-23-producing monocytes while other monocyte clusters remained largely unaffected (Figure 6C and 6D). Importantly, monocyte IL-23 production induced by uptake of whole bacteria was similarly dependent on IL-1R1 signalling (Supplementary Fig. 9A and 9B) suggesting that IL-23 is downstream of IL-1 signalling also in the context bacteria-induced functional IL-10 signalling defects.

\section{A mathematical model of IL-23 regulation in monocytes}

To investigate the impact of cytokine networks on monocyte IL-23 production in more detail we analysed the effects of cytokines up-stream of IL-23 using a mathematical model of ordinary differential equations. Those describe interactions of monocyte-produced IL-23, TNF, 
IL-1 $\alpha$, IL-1 $\beta$, IL-6, and IL-10 at the 16-hours time point. We identified an initial set of cytokine interactions, i.e. changes in cytokine production after addition or blockade of a cytokine (FDR corrected paired Wilcoxon test, Figure 7A). Then, we modelled all feasible network configurations, noting that most of the $n=2^{31}-1$ configurations could be excluded a priori. We identified an optimal network describing the core network dynamics by ranking the models based on their fit to the data using the Akaike information criterion (Figure 7B). The model correctly identifies IL-10 signalling as negative feedback mechanism and IL-1 $\beta$ as a positive regulator (with IFN- $\gamma$ as an amplifier) of IL-1 $\alpha$, IL-6 and IL-23 expression.

To confirm these predictions, we investigated the effect of IL-1R1 blockade on IL-23 expression in the context of genetic deficiency of IL-10 signalling. We stimulated PBMC obtained from patients with infantile onset IBD due to an IL10RA or IL10RB gene defect (Figure 7C). Interestingly, patient-derived monocytes produced IL-23 in response to LPS stimulation alone, indicating the intrinsic defect in IL-10R-dependent regulation, confirmed by the inability of exogenous IL-10 to suppress monocyte IL-1 $\beta$ production. Strikingly, IL-1R1 blockade inhibited monocyte IL-23 production in LPS-stimulated PBMC from IL-10R deficient patients (Figure 7D). Together, these analyses confirmed IL-10 as the major negative regulator of IL-23 production, while IL-1 signalling (and in particular IL-1 $\beta$ ) is essential for monocyte IL-23 synthesis.

\section{DISCUSSION}

We identify key regulatory circuits of IL-23 production by inflammatory monocytes. These include failure of paracrine IL-10-mediated control as well as autocrine and paracrine signalling of IL- $1 \alpha$ and IL-1 $\beta$ in response to inflammatory stimuli. Indeed, increased IL-23 production can be observed in monocytes from patients with infantile onset Mendelian IL-10 signalling deficiency or experimental blockade of the IL-10 receptor, but also monocytes that respond to whole bacteria express IL-23 as a consequence of acquired IL-10 nonresponsiveness. Most importantly, we define a transcriptional signature of IL- $23^{+}$inflammatory monocytes that indicates a state of acquired IL-10 non-responsiveness in a subgroup of patients with deep ulcers and compromised epithelial function where monocytes may directly respond to whole bacteria. This signature predicts both diagnosis of CD and resistance to anti-TNF treatment similar to previously described OSM expression ${ }^{18}$. Interestingly, loss of IL-10 responsiveness induces $I L 23 \mathrm{~A}$ mRNA and IL-23 protein expression only in a small fraction of monocytes that express the IL-1 receptor IL1RI. This selective IL-23 expression contrasted 
with pervasive induction of IL-1 $\alpha$ and IL-1 $\beta$ expression as well as a broad induction of IL-10 expression in monocytes under the same hyper-inflammatory condition.

Our data support context-specific roles of IL-23 in driving the differentiation of pathogenic Th17/Th1 cells in presence of IL- ${ }^{27}$ that are enriched in inflamed intestinal tissue from patients with $\mathrm{IBD}^{28,29}$, while supporting the development of non-pathogenic Th17 cells under homeostatic conditions such as those found in mucosa-associated lymphoid tissue (MALT) - in healthy individuals.

Together, these results suggest that only subgroups of patients with active disease may benefit from anti-IL-23p19 therapy, and that the targeting of upstream cytokines that regulate IL-23 expression in inflammation, such as IL-1 might provide a selective means to block pathogenic IL-23 expression.

The critical element that differentiates homeostatic IL-23 and TNF expression from hyper-inflammation is the co-expression of a multitude of IL-10-regulated factors, including IL- $1 \alpha$ and IL-1 $\beta$ in patients with severe active disease and anti-TNF treatment nonresponsiveness.

The strong predictive ability of an IL-10 sensitive inflammatory monocyte signature (CD14, IL1A, IL1B, OSM, PTGS2, IL6, CCL2/3 and CXCL1/2) emphasises a surprising and underestimated extent of IL-10 non-responsiveness in IBD. In those patients inflammation is present despite transcription of IL-10 (patients express large amount of IL-10) and absence of pathogenic variants within the IL-10 receptor (exome sequencing did not reveal Mendelian forms of IL-10 receptor signalling defects in this cohort ${ }^{30}$ ). The high expression of PTGS2 in this subgroup of patients with IBD represents an additional indicator for deregulated IL-10 responses and intestinal antimicrobial immunity ${ }^{31}$. Our experiments suggest that direct contact of monocytes with whole bacteria can induce IL-10 resistance that allows co-expression of IL23 and IL-1 explain the signature of IL-10 non-responsiveness in a subgroup of patients with intestinal ulceration. An additional mechanism of reduced IL-10 responsiveness may be differential expression of IL-10R $1^{32}$. Our ELISpot experiments exclude differential spatial clustering of IL-10 or IL-23 secreting monocytes as well as oscillatory or sequential IL-10 and IL-23 transcription. This suggests that the inflammatory microenvironment drives in parallel several monocyte effector programs and monocyte to macrophage and DC differentiation processes, reminiscent to plasmacytoid dendritic cells (pDC) stimulation with a single stimulus (R848 or $\mathrm{CpG}$ ) of that induces diverse transcriptional states and cellular functions ${ }^{33}$. This is likely a biological mechanism to ensure functional heterogeneity under hyper-inflammatory 
conditions, when diversity in the host defence towards a range of potential pathogens is essential.

Single cell RNA transcriptomic approaches identified transcriptional signatures in circulating and tissue human monocytes and macrophages ${ }^{9,34-38}$ demonstrating phenotypic and functional diversity in monocyte, macrophage and DC populations. We have focused on the cellular heterogeneity and inflammatory response of peripheral monocytes, because those cells are recruited into the gut and differentiate into pro-inflammatory MHC-II-high monocytes and macrophages that outnumber resident, yolk-sac derived tissue macrophages during inflammation ${ }^{39-41}$. Such pro-inflammatory macrophages have been characterized following in vitro differentiation using LPS-stimulation and express IL-12 and IL-23 in response to STAT1dependent IFN- $\gamma$ signalling ${ }^{42}$.

Our data suggest that the source of IL-23 in the context of inflammasome activation and IL-1 production in the inflamed intestine are inflammatory monocytes and CX3CR $1^{+} \mathrm{IL}-$ $1 \beta^{+}$positive macrophages ${ }^{43,44}$. In individuals without intestinal inflammation, our network analysis suggested that IL23A expression was likely derived from terminal ileal MALT because the "lymphocyte differentiation" to which it was assigned also showed strong correlations with orthologs of genes associated with murine small intestine lymphoid tissue (SILT) including IL22RA2, ITGA $X^{27}$ as well as with $V C A M 1$, which is a marker of lymphoid associated villi in humans (Supplementary Fig. 5B). In such MALT tissue, which is hyperplastic in paediatric patients $^{45}$ the source of $I L 23 \mathrm{~A}$ is most likely dendritic cells (DC), tolerogenic CD103 ${ }^{+} \mathrm{DC}^{46}$ or macrophages as is known to be the case in mouse SILT ${ }^{43}$. This work demonstrates the utility of network-based approaches for deconvolving variance in gene expression that arises from the analysis of biopsy samples from tissues with complex micro-anatomical heterogeneity such as the small intestine.

Our mathematical model pin-points IL-1 as a key positive regulator of IL-23 expression in monocytes. Studies in monogenic forms of IBD suggest that IL-1R1 blockade can resolve intestinal inflammation in patients with IL-10 receptor defects ${ }^{47}$, mevalonate kinase defects and potentially gain of function $\mathrm{NLRC}^{48}$ defects, which are all characterised by increased inflammasome activation and IL-1 secretion. It is therefore an attractive hypothesis that the hyperinflammatory $\mathrm{IL}^{+}{ }^{+} \mathrm{PTGS}^{+} \mathrm{IL}^{+}{ }^{+}$signature might define an anti-IL-1R1 responsive group of patients with IBD. Interventional studies are required to identify differential effects between IL-23 and IL-1 blockade since both have complex effects on licensing for effector cytokine production and differentiation of Th1 and Th17 cells ${ }^{49}$. Altogether our findings may inform 
bioRxiv preprint doi: https://doi.org/10.1101/719492; this version posted January 31, 2020. The copyright holder for this preprint (which was not certified by peer review) is the author/funder, who has granted bioRxiv a license to display the preprint in perpetuity. It is made available under aCC-BY-NC-ND 4.0 International license.

transcriptional diagnostic efforts to guide use of IL-23p19 targeting therapies and suggest a role for therapeutics capable of selectively blocking IL-23 in disease by targeting contextspecific upstream factors such as IL-1. 


\section{REFERENCES}

1. Uhlig HH, Powrie F. Translating Immunology into Therapeutic Concepts for Inflammatory Bowel Disease. Annu Rev Immunol 2018;36:755-781.

2. Mirkov MU, Verstockt B, Cleynen I. Genetics of inflammatory bowel disease: beyond NOD2. Lancet Gastroenterol Hepatol 2017;2:224-234.

3. Duerr RH, Taylor KD, Brant SR, et al. A genome-wide association study identifies IL23R as an inflammatory bowel disease gene. Science 2006;314:1461-3.

4. Jostins L, Ripke S, Weersma RK, et al. Host-microbe interactions have shaped the genetic architecture of inflammatory bowel disease. Nature 2012;491:119-24.

5. de Lange KM, Moutsianas L, Lee JC, et al. Genome-wide association study implicates immune activation of multiple integrin genes in inflammatory bowel disease. Nat Genet 2017;49:256-261.

6. Hue S, Ahern P, Buonocore S, et al. Interleukin-23 drives innate and T cell-mediated intestinal inflammation. J Exp Med 2006;203:2473-83.

7. Uhlig HH, McKenzie BS, Hue S, et al. Differential activity of IL-12 and IL-23 in mucosal and systemic innate immune pathology. Immunity 2006;25:309-18.

8. Neurath MF. Current and emerging therapeutic targets for IBD. Nat Rev Gastroenterol Hepatol 2017;14:269-278.

9. Martin JC, Chang C, Boschetti G, et al. Single-Cell Analysis of Crohn's Disease Lesions Identifies a Pathogenic Cellular Module Associated with Resistance to AntiTNF Therapy. Cell 2019;178:1493-1508 e20.

10. Friedrich M, Pohin M, Powrie F. Cytokine Networks in the Pathophysiology of Inflammatory Bowel Disease. Immunity 2019;50:992-1006.

11. Yen D, Cheung J, Scheerens H, et al. IL-23 is essential for T cell-mediated colitis and promotes inflammation via IL-17 and IL-6. J Clin Invest 2006;116:1310-6.

12. Feagan BG, Sandborn WJ, D'Haens G, et al. Induction therapy with the selective interleukin-23 inhibitor risankizumab in patients with moderate-to-severe Crohn's disease: a randomised, double-blind, placebo-controlled phase 2 study. Lancet 2017;389:1699-1709.

13. Sands BE, Chen J, Feagan BG, et al. Efficacy and Safety of MEDI2070, an Antibody Against Interleukin 23, in Patients With Moderate to Severe Crohn's Disease: A Phase 2a Study. Gastroenterology 2017;153:77-86 e6.

14. Cleynen I, Boucher G, Jostins L, et al. Inherited determinants of Crohn's disease and ulcerative colitis phenotypes: a genetic association study. Lancet 2016;387:156-67.

15. Lee JC, Biasci D, Roberts R, et al. Genome-wide association study identifies distinct genetic contributions to prognosis and susceptibility in Crohn's disease. Nat Genet 2017;49:262-268.

16. Lee JC, Lyons PA, McKinney EF, et al. Gene expression profiling of CD8+ T cells predicts prognosis in patients with Crohn disease and ulcerative colitis. J Clin Invest 2011;121:4170-9.

17. Biasci D, Lee JC, Noor NM, et al. A blood-based prognostic biomarker in IBD. Gut 2019;68:1386-1395.

18. West NR, Hegazy AN, Owens BMJ, et al. Oncostatin M drives intestinal inflammation and predicts response to tumor necrosis factor-neutralizing therapy in patients with inflammatory bowel disease. Nat Med 2017;23:579-589.

19. Gaujoux R, Starosvetsky E, Maimon N, et al. Cell-centred meta-analysis reveals baseline predictors of anti-TNFalpha non-response in biopsy and blood of patients with IBD. Gut 2019;68:604-614. 
20. Kugathasan S, Denson LA, Walters TD, et al. Prediction of complicated disease course for children newly diagnosed with Crohn's disease: a multicentre inception cohort study. Lancet 2017;389:1710-1718.

21. Haberman Y, Tickle TL, Dexheimer PJ, et al. Pediatric Crohn disease patients exhibit specific ileal transcriptome and microbiome signature. J Clin Invest 2014;124:3617-33.

22. Arijs I, Li K, Toedter G, et al. Mucosal gene signatures to predict response to infliximab in patients with ulcerative colitis. Gut 2009;58:1612-9.

23. Arijs I, De Hertogh G, Lemaire K, et al. Mucosal gene expression of antimicrobial peptides in inflammatory bowel disease before and after first infliximab treatment. PLoS One 2009;4:e7984.

24. Baillie JK, Arner E, Daub C, et al. Analysis of the human monocyte-derived macrophage transcriptome and response to lipopolysaccharide provides new insights into genetic aetiology of inflammatory bowel disease. PLoS Genet 2017;13:e1006641.

25. Glocker EO, Kotlarz D, Boztug K, et al. Inflammatory bowel disease and mutations affecting the interleukin-10 receptor. N Engl J Med 2009;361:2033-45.

26. Zhang B, Horvath S. A general framework for weighted gene co-expression network analysis. Stat Appl Genet Mol Biol 2005;4:Article17.

27. Zielinski CE, Mele F, Aschenbrenner D, et al. Pathogen-induced human TH17 cells produce IFN-gamma or IL-10 and are regulated by IL-1beta. Nature 2012;484:514-8.

28. Kleinschek MA, Boniface K, Sadekova S, et al. Circulating and gut-resident human Th17 cells express CD161 and promote intestinal inflammation. J Exp Med 2009;206:525-34.

29. Aschenbrenner D, Foglierini M, Jarrossay D, et al. An immunoregulatory and tissueresidency program modulated by c-MAF in human TH17 cells. Nat Immunol 2018;19:1126-1136.

30. Denson LA, Jurickova I, Karns R, et al. Clinical and Genomic Correlates of Neutrophil Reactive Oxygen Species Production in Pediatric Patients With Crohn's Disease. Gastroenterology 2018;154:2097-2110.

31. Mukhopadhyay S, Heinz E, Porreca I, et al. Loss of IL-10 signaling in macrophages limits bacterial killing driven by prostaglandin E2. J Exp Med 2020;217.

32. Nunberg MY, Werner L, Kopylov U, et al. Impaired IL-10 Receptor-mediated Suppression in Monocyte From Patients With Crohn Disease. J Pediatr Gastroenterol Nutr 2018;66:779-784.

33. Alculumbre SG, Saint-Andre V, Di Domizio J, et al. Diversification of human plasmacytoid predendritic cells in response to a single stimulus. Nat Immunol 2018;19:63-75.

34. Smillie CS, Biton M, Ordovas-Montanes J, et al. Intra- and Inter-cellular Rewiring of the Human Colon during Ulcerative Colitis. Cell 2019;178:714-730 e22.

35. Dixit A, Parnas O, Li B, et al. Perturb-Seq: Dissecting Molecular Circuits with Scalable Single-Cell RNA Profiling of Pooled Genetic Screens. Cell 2016;167:1853-1866 e17.

36. Villani AC, Satija R, Reynolds G, et al. Single-cell RNA-seq reveals new types of human blood dendritic cells, monocytes, and progenitors. Science 2017;356.

37. Cohen M, Giladi A, Gorki AD, et al. Lung Single-Cell Signaling Interaction Map Reveals Basophil Role in Macrophage Imprinting. Cell 2018;175:1031-1044 e18.

38. Bujko A, Atlasy N, Landsverk OJB, et al. Transcriptional and functional profiling defines human small intestinal macrophage subsets. J Exp Med 2018;215:441-458.

39. Kamada N, Hisamatsu T, Okamoto S, et al. Unique CD14 intestinal macrophages contribute to the pathogenesis of Crohn disease via IL-23/IFN-gamma axis. J Clin Invest 2008;118:2269-80. 
40. Rivollier A, He J, Kole A, et al. Inflammation switches the differentiation program of Ly6Chi monocytes from antiinflammatory macrophages to inflammatory dendritic cells in the colon. J Exp Med 2012;209:139-55.

41. Stagg AJ. Intestinal Dendritic Cells in Health and Gut Inflammation. Front Immunol 2018;9:2883.

42. Glass CK, Natoli G. Molecular control of activation and priming in macrophages. Nat Immunol 2016;17:26-33.

43. Savage AK, Liang HE, Locksley RM. The Development of Steady-State Activation Hubs between Adult LTi ILC3s and Primed Macrophages in Small Intestine. J Immunol 2017;199:1912-1922.

44. Shaw MH, Kamada N, Kim YG, et al. Microbiota-induced IL-1beta, but not IL-6, is critical for the development of steady-state TH17 cells in the intestine. J Exp Med 2012;209:251-8.

45. Senda T, Dogra P, Granot T, et al. Microanatomical dissection of human intestinal Tcell immunity reveals site-specific changes in gut-associated lymphoid tissues over life. Mucosal Immunol 2019;12:378-389.

46. Longman RS, Diehl GE, Victorio DA, et al. CX(3)CR1(+) mononuclear phagocytes support colitis-associated innate lymphoid cell production of IL-22. J Exp Med 2014;211:1571-83.

47. Shouval DS, Biswas A, Kang YH, et al. Interleukin 1beta Mediates Intestinal Inflammation in Mice and Patients With Interleukin 10 Receptor Deficiency. Gastroenterology 2016;151:1100-1104.

48. Holzinger D, Kessel C, Omenetti A, et al. From bench to bedside and back again: translational research in autoinflammation. Nat Rev Rheumatol 2015;11:573-85.

49. Gaffen SL, Jain R, Garg AV, et al. The IL-23-IL-17 immune axis: from mechanisms to therapeutic testing. Nat Rev Immunol 2014;14:585-600. 


\section{SUPPLEMENTARY EXPERIMENTAL PROCEDURES}

\section{Patient cohort - RISK cohort and outcome classification:}

The RISK study is an observational prospective cohort study with the aim to identify risk factors that predict complicated course in pediatric patients with Crohn's disease ${ }^{20}$. The RISK study recruited treatment-naive patients with a suspected diagnosis of Crohn's disease. The Paris modification of the Montreal classification were used to classify patients according to disease behaviour (non-complicated B1 disease (non-stricturing, non-penetrating disease); complicated disease, composed of B2 (stricturing) and/or B3 (penetrating) behaviour) as well as disease location (L1, ileal only, L2, colonic only, L3, ileocolonic and L4, upper gastrointestinal tract). 322 samples were investigated with ileal RNA-seq. Individuals without ileal inflammation were classified as non-IBD controls. Patients with Crohn's disease were followed over a period of 3 years. Patients were largely of European (85.7\%) and African $(4.1 \%)$ ancestry.

\section{Cell culture and stimulation:}

For stimulation assays, $0.5 \times 10^{6}-1 \times 10^{6}$ PBMC or MACS-purified CD14 $4^{+}$monocytes (Mitenyi Biotec) were cultured in $200 \mu \mathrm{l}$ medium in duplicates in round bottom 96-well plates and exposed to ultrapure 200 ng/ml LPS (Enzo Life Sciences; Cat.\# ALX-581-008), 200 ng/ml L18MDP (Invivogen) $10 \mu \mathrm{g} / \mathrm{ml}$ anti-IL-10R (Biolegend; clone: 3F9), anti-CD3/anti-CD28 beads (Invitrogen) or Staphylococcal enterotoxin B (SEB; Sigma) for the indicated time in complete RPMI with L-glutamine (Sigma) supplemented with $10 \%$ human serum (Sigma; Cat.\# H4522), non-essential amino acids (Gibco); $1 \mathrm{mM}$ Sodium-Pyruvate (Gibco) and 100 $\mathrm{U} / \mathrm{ml}$ penicillin and $10 \mu \mathrm{g} / \mathrm{ml}$ streptomycin (Sigma). Supernatants were collected and stored at $-80{ }^{\circ} \mathrm{C}$ for the quantification of cytokine production. The following neutralizing antibodies or receptor blocking antibodies were used (all $10 \mu \mathrm{g} / \mathrm{ml}$ ): anti-IL-24 (R\&D; Cat.\# AF1965; Polyclonal Goat IgG), anti-IL-12p70 (R\&D; Cat.\# MAB219; clone 24910), anti-IL-19 (R\&D; Cat.\# MAB10351; clone 152107), anti-GM-CSF (R\&D; Cat.\# MAB215; clone 3209), anti-IL-

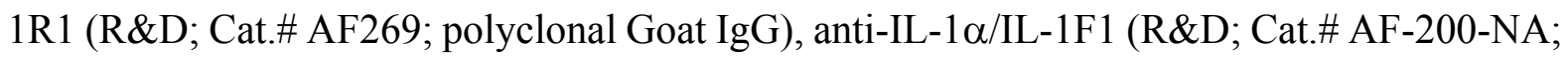
polyclonal Goat IgG), anti-IL-1ß/IL-1F2 (R\&D; Cat.\# MAB201; clone: 8516), anti-IL-6R (Tocilizumab, Actemra ${ }^{\circledR}$, Roche,), anti-TNF $\alpha$ (Infliximab, REMICADE®, Janssen), antiIFN $\alpha / \beta R 2$ (Millipore; Cat.\# MAB1155; clone: MMHAR-2), anti-IL-10R (Biolegend; Cat.\# 308807; clone: 3F9), anti-IL-10 (R\&D; Cat.\# MAB217; clone: 23738), anti-IFN $\gamma$ (Biolegend; 


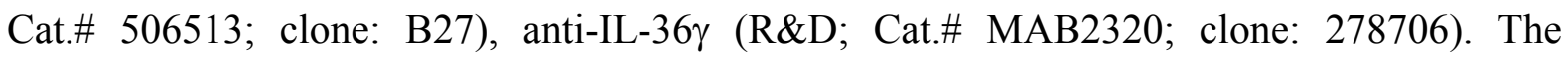
following recombinant human cytokines were used (all $10 \mathrm{ng} / \mathrm{ml}$ ): IL-1 $\beta$ (Preprotech), IL-6 (Preprotech), IL-10 (Preprotech), IL-11 (R\&D), IL-12 (Preprotech), IL-17A (Preprotech), IL18 (R\&D), IL-23 (Preprotech), GM-CSF (Preprotech), IFN $\gamma$ (Preprotech), TNF $\alpha$ (Preprotech).

\section{Whole bacteria preparation and stimulation:}

Both Salmonella enterica serovar Typhimurium (ST) expressing green-fluorescent protein (GFP) (NCTC 12023) $)^{52}$ and Escherichia coli Nissle $1917^{53}(\mathrm{EcN})$ were grown overnight in LB (Sigma) and the O.D was measured on the following day at $650 \mathrm{~nm}$. Aliquots corresponding to $10^{9}$ particles of bacterial were centrifuged at $6000 \mathrm{rpm}$ for 5 minutes and the pellet was washed twice in the fresh LB then twice in PBS (Sigma). Cells were then heat-killed at $65^{\circ} \mathrm{C}$ for 30 minutes and stored in aliquots at $-20^{\circ} \mathrm{C}$ till further use. For monocyte stimulation assays, $0.1 \times 10^{6}$ MACS-purified CD14 ${ }^{+}$monocytes (Mitenyi Biotec) were cultured in $150 \mu 1$ medium in duplicates in round bottom 96-well plates and exposed to combinations of ST (monocyte to bacteria ratio $=1: 2$ ), $\mathrm{EcN}$ (monocyte to bacteria ratio $=1: 2$ ), ultrapure $200 \mathrm{ng} / \mathrm{ml}$ LPS (Enzo Life Sciences; Cat.\# ALX-581-008), $10 \mu \mathrm{g} / \mathrm{ml}$ anti-IL-10R (Biolegend; clone: 3F9), $10 \mu \mathrm{g} / \mathrm{ml}$ anti-IL-10 (R\&D; Cat.\# MAB217; clone: 23738), 10 gg/ml anti-IL-1R1 (R\&D; Cat.\# AF269; polyclonal Goat IgG) for 16 hours (the last 4 hours of culture in the presence of BFA (Sigma) in the case of intracellular staining) in complete RPMI with L-glutamine (Sigma) supplemented with $10 \%$ human serum (Sigma; Cat.H4522), non-essential amino acids (Gibco); $1 \mathrm{mM}$ Sodium-Pyruvate (Gibco) and $100 \mathrm{U} / \mathrm{ml}$ penicillin and $10 \mu \mathrm{g} / \mathrm{ml}$ streptomycin (Sigma).

\section{Protein level analysis:}

Cytokine levels in the supernatants were assayed using the Milliplex human cytokine/chemokine magnetic bead 41-plex panel (Milliplex Billerica, MA, USA; HCYTOMAG-60K-PX41) and acquired on a Luminex LX200 flow reader. IL-23p19 cytokine level was assayed using a MSD (Meso Scale Discovery) in-house assay. In short, an IL-23p19 selective antibody (Ab1, clone \#32) was biotinylated following the Biotin, EZ-Link ${ }^{\text {TM NHS- }}$ PEG4-Biotin instructions (ThemoScientific, Cat.\# 2161299). For detection, an anti-p40 antibody (Ab-2, clone \#42) was sulfotaged according to manufactures instructions (MSD Gold Sulfo-Tag NHS; Cat.\# R91A0-1 and MSD Gold Sulfo-Tag NHS-Ester Conjugation Packs; Cat.\# R31AA-1). MSD Streptavidin Gold plates (MSD; Cat.\# L15SA-1) were washed, blocked, coated with biotinylated Ab-1, and washed according the manufacture instruction. 50 
$\mathrm{ul}$ of supernatant or standard were added to the plate and incubated overnight at $4{ }^{\circ} \mathrm{C}$ while shaking. Plates were washed 3 times and detection antibody was added and incubated for $2 \mathrm{hrs}$ while shaking at room temperature. Plates were washed and read buffer added. Plates were read with a MSD reader Quick Plex S120.

\section{Surface marker analyses by flow cytometry:}

The expression of cell surface markers was analysed by staining for $15 \mathrm{~min}$ at room temperature (RT) in PBS supplemented with $0.5 \%$ (v/v) human serum (FACS buffer). To allow exclusion of dead cells, cells were stained prior to fixation using Fixable Viability Dye eFluor ${ }^{\circledR} 780$ (eBioscience). Following fluorophore-conjugated antibodies were used for analysis (supplier, clone): anti-CD3 (BD Biosciences; UCHT1), anti-CD4 (Biolegend; RPA-T4), anti-CD8 (Biolegend; SK1), anti-CD14 (Biolegend; M5E2), anti-CD16 (Biolegend; 3G8), anti-CD19 (BD Biosciences; SJ25C1), anti-CD25 (Biolegend; MA-A251), anti-CD45RA (Biolegend; HI100), anti-CD56 (BD Biosciences; NCAM16.2), anti-HLA-DR (Biolegend; L243). For combined analysis of surface marker and intracellular cytokines, surface-stained cells where subsequently stained as described in the section Intracellular cytokine staining. Data were acquired on a LSRII flow cytometer (BD Biosciences).

\section{Intracellular cytokine staining (ICCS):}

Cells were stimulated in the presence of brefeldin A (BFA, $10 \mu \mathrm{g} / \mathrm{ml}$, all from Sigma) for the final 4 hours of cell culture. Cells were fixed and permeabilised with Cytofix/Cytoperm (BD Biosciences) according to the manufacturer's instructions. To exclude dead cells from the analysis, cells were stained prior to fixation using Fixable Viability Dye eFluor ${ }^{\circledR} 780$ (eBioscience). Following fluorophore-conjugated anti-cytokine antibodies were used for analysis (supplier; clone): anti-IL-1 $\alpha$ (Biolegend; 364-3B3-14), anti-IL-1 $\beta$ (Biolegend; H1b98), anti-IL-4 (BD Biosciences; MP4-25D2), anti-IL-6 (eBioscience; MQ2-13A5), anti-IL-10 (Biolegend; JES3-9D7), anti-IL-13 (eBioscience: 85BRD), anti-IL-17A (eBioscience; eBio64DEC17), anti-IL-23p19 (eBioscience; 23dcdp), anti-GM-CSF (BD Biosciences; BVD2-21C11), anti-IFN- $\gamma$ (eBioscience; 4S.B3), anti-TNF (Biolegend: MAb11). For the detection of IL-12p40 the combination of biotin-conjugated anti-IL-12p40 (BD Biosciences; C8.6) and streptavidin STV-CF594 (BD Biosciences; Cat.\# 562318) were used. Data were acquired on a LSRII flow cytometer (BD Biosciences). 


\section{Monocyte cluster validation and $t$ SNE analysis of flow cytometry data:}

For the validation of scRNA-seq-identified monocyte clusters at the protein level, cells were stained for the following marker (supplier; clone): anti-CD14 (Biolegend; M5E2), anti-HLADR (Biolegend; L243), anti-CCL20/MIP-3 alpha (R\&D; 67310), anti-CCL20/MIP-3 alpha (R\&D; 114906), anti-IL-23p19 (eBioscience; 23dcdp), anti-CCL2 (eBioscience; 5D3-F7), anti-RPS6 (R\&D; 522731), anti-SPINK1 (R\&D; 839305), anti-IDO-1 (eBioscience; Eyedio), EBI3 (eBioscience; ebic6), anti-S100A8 (Invitrogen: CF-145), anti-S100A9 (Biolegend, MRP14), anti-TNF (Biolegend: MAb11). Unconjugated antibodies targeting RPS6 and SPINK were conjugated in house using the Expedeon (Innova Biosciences) Lightning-Link PE/Texas Red or DyLight 405 antibody labelling kit according to the manufacturer's instructions, respectively. t-Distributed Stochastic Neighbor Embedding (TSNE)-based analysis was executed on FCS files compensated for spillover between channels and gated on live CD3 ${ }^{-}$ $\mathrm{CD}^{-} 9^{-} \mathrm{CD} 56^{-} \mathrm{CD} 14^{+}$single cells, down-sampled to 3.000 cells per sample. A single FCS file was generated by concatenating individual samples FCS files prior to tSNE unsupervised analysis using the FlowJo (Treestar) tSNE plugin ${ }^{54,55}$ based on cluster defining genes. The following settings were used: Iterations $=1000 ;$ Perplexity $=200 ; \mathrm{Eta}=20$; Theta $=0.5$. and included the following parameters: CD14, HLA-DR, CCL2, CCL20, IL-23p19, IDO-1, RPS6, SPINK1, S100A8 and TNF. IL-23 ${ }^{+}$inflammatory monocytes were defined by combined IL23p19, CCL20 and TNF expression, IFN-induced monocytes were defined by combined HLADR and IDO-1expression; microbicidal monocytes were defined by combined CCL2, S100A8 and CD14 expression and apoptotic monocytes were identified by combined RPS6 and SPINK1expression).Each individual analysis was performed on samples that were stained and acquired (LSRII (BD Biosciences)) on the same day.

\section{Analysis of cytokine-induced STAT3 phosphorylation by flow cytometry:}

Whole blood $(\triangle I L 10 R A)$ or PBMC $(\triangle I L 10 R B)$ were surface stained with anti-CD3-PE-Cy5 or anti-CD3-FITC (Biolegend; clone: UCHT1), anti-CD4-BV605 (Biolegend; clone: OKT4), anti-CD8-PE-CF594 (BD Biosciences; clone: RPA-T8), anti-CD14-BV650 (Biolegend; clone: M5E2), and anti-CD19-BV711 (BD biosciences; clone: HIB19 or clone: SJ25C1) for 20 min. Five minutes through surface staining, cells were stimulated with $100 \mathrm{ng} / \mathrm{ml}$ human recombinant IL-10 or IL-6 (Peprotech) for $15 \mathrm{~min}$. Cells were subsequently fixed in prewarmed $\left(37^{\circ} \mathrm{C}\right) \mathrm{BD}$ Cytofix for 10 minutes (BD biosciences) at $37^{\circ} \mathrm{C}$. After fixation, cells were permeabilised on ice with ice-cold Perm Buffer III (BD biosciences) and stained with anti- 
pSTAT3 (pY705)-Alexa Fluor 647 (4/P-STAT3, BD Phosflow) for $1 \mathrm{~h}$ at room temperature before acquiring on a LSRII flow cytometer (BD Biosciences). For the analysis of IL-10 responsiveness in stimulated monocytes, cells were washed (2 times) in RPMI (Sigma) and incubated in RPMI for 2 hours. Following incubation, cells were washed ( 2 times) in RPMI and stimulated for 15 minutes in complete RPMI with $50 \mathrm{ng} / \mathrm{ml}$ recombinant human IL-10 (Preprotech). Cell were then stained in PBS (Sigma) on ice with Fixable Viability Dye eFluor ${ }^{\circledR}$ 780 (eBioscience). Subsequently, cells were fixed, permeabilised and stained as described above.

\section{IL-10 and IL-23 ELISpot assay:}

ELISpot plates (Merck; Cat.\#MSHAS4510) were incubated with sterile PBS (Gibco) and coated over night at $4^{\circ} \mathrm{C}$ with anti-IL-12/IL-23p40 (Mabtech; Cat.\# MT86/221; $10 \mu \mathrm{g} / \mathrm{ml}$ in PBS) and anti-IL-10 (Mabtech; Cat.\# 9D7;15 $\mu \mathrm{g} / \mathrm{ml}$ in PBS) antibodies using $100 \mu 1 /$ well. On the next day plates were flicked and blocked using $100 \mu \mathrm{l} /$ well 1x sterile PBS (Gibco) supplemented with $10 \%$ FCS (Sigma) for 2 hours at $37^{\circ} \mathrm{C}$. Following, the buffer was removed and MACS-purified monocytes were plated at 2-fold concentration steps ranging from 6250 to 50.000 cells/well in complete RPMI medium supplemented with 10\% FCS. Stimulation and incubation was performed over night at $37^{\circ} \mathrm{C}$ and $5 \% \mathrm{CO} 2$ using combinations of LPS (200 $\mathrm{ng} / \mathrm{ml})$ and IL-10R blocking antibody $(10 \mu \mathrm{g} / \mathrm{ml})$. Following 16 hours incubation, cells were removed by flicking the plate and wells were washed extensively 10 times, each 1 minute incubation, with $200 \mu \mathrm{l}$ washing buffer $(0.1 \%$ Tween20 (Sigma) in PBS (Gibco). Secondary antibodies were diluted in PBS supplemented with 0.5\% FCS (anti-IL-IL-23p19 (Mabtech; Cat.\#/clone: MT155-HRP; $1 \mu \mathrm{g} / \mathrm{ml}$ ) and anti-IL-10-biotin (Mabtech; Cat.\#/clone: 12G8: 1 $\mu \mathrm{g} / \mathrm{ml}) .100 \mu \mathrm{l} /$ well antibody mixture was added to each well and incubation was performed for 2 hours at $37^{\circ} \mathrm{C}$. Plates were then washed extensively 10 times, each 1 minute incubation. For the development of spots first $100 \mu \mathrm{l} /$ well substrate solution (BCIP/NBT; Sigma) was added and development continued until distinct blue/grey spots emerged (approximately 5 minutes). Plates were again extensively washed 10 times, each 1 minute incubation, with 200 $\mu \mathrm{l}$ washing buffer. Then $100 \mu \mathrm{l} /$ well substrate solution (AEC; BD Pharmingen) was added to each well and development was continued until distinct red spots emerged (approximately 5 minutes). Plates were left to dry in the dark and images were acquired using an AID EliSpot Reader Systems. The anti-IL-10 clone 12G8 was conjugated with biotin (Novus Biologicals Lightning-Link Rapid Type A Biotin Antibody Labeling Kit). 


\section{Generation and pre-processing of single-cell RNA-sequencing data:}

$\mathrm{CD} 14^{+}$monocytes were purified from PBMC by MACS positive selection (Mitenyi Biotec) according to the manufacturers' instructions from 2 human donors. The purity of sorting and viability was assessed by surface staining and flow cytometry (anti-CD14 (Biolegend; M5E2); Fixable Viability Dye eFluor ${ }^{\circledR} 780$ (eBioscience). Cells were plated in 96-well U-bottom plates at a cell density of $0.5 \times 10^{6}$ cells/well in $200 \mu \mathrm{l}$ complete RPMI and were left unstimulated or exposed to combinations of ultrapure $200 \mathrm{ng} / \mathrm{ml}$ LPS (Enzo Life Sciences; Cat.\# ALX-581-008) and $10 \mu \mathrm{g} / \mathrm{ml}$ anti-IL-10R (Biolegend; clone: 3F9) for 16 hours. For droplet-based single cell RNA-sequencing analysis cells were collected in RPMI with Lglutamine (Sigma) supplemented with 0.5\% human serum (Sigma; Cat.\# H4522) and the cell number was adjusted to 1000 cells/ $\mu 1$. Single cell suspensions were kept on ice, washed in PBS with $0.04 \%$ BSA and resuspended. 10.000 single cells/channel were captured in droplets on Chromium 10x Genomics platform (less than one hour following the termination of stimulation). Library generation for $10 \mathrm{x}$ Genomics $\mathrm{v} 2$ chemistry was performed following the Chromium Single Cell 3' Reagents Kits User Guide (CG00052). Quantification of library was performed using an Agilent Bioanalyzer and Bioanalyzer High Sensitivity DNA Reagents (Cat.\# 5067-4627). Single-cell RNA-sequencing libraries were generated using the 10x Genomics Single Cell 3' Solution (version 2) kit and sequenced to a minimum mean depth of 44.3k reads/cell (Illumina HiSeq 4000). An average of 2850 cells/per sample and 1150 genes/cell were recovered. Data analysis was performed using Python3 pipelines (https:/github.com/sansomlab/tenx) written using the CGAT-core library \#https://doi.org/10.12688/f1000research.18674.1. Read mapping, quantitation and aggregation of sample count matrices was performed with the 10x Genomics Cell Ranger pipeline (version 2.1.1) and version 1.2.0 (GRCh38) reference sequences. No normalisation was applied during the aggregation step. Cells with barcodes common to samples sequenced on the same lane(s) were removed from the analysis to avoid issues associated with index hopping. Aggregated count matrices were randomly down-sampled in order to normalise the median number of UMIs per-cell between the samples ("downsampleMatrix" function from the DropletUtils R package). Down-sampling was performed separately for the within-donor cross-condition analysis (Figure 3) and the cross-donor analysis of LPS + anti-IL10R stimulated monocytes (Supplementary Fig. 4b). 


\section{Cross-condition analysis of single-cell RNA-sequencing data from a single} donor:

The dataset was filtered to remove cells with $<500$ genes, $>5 \%$ mitochondrial reads per cell or that expressed lymphocyte markers $(C D 3, C D 79 A$ or $C D 79 B, \mathrm{n}=33$ cells) leaving a total of $\mathrm{n}=2420$ unstimulated, $\mathrm{n}=3149$ LPS stimulated and $\mathrm{n}=2273$ LPS + anti-IL-10R stimulated monocytes. Per-cell UMI counts were then normalised, scaled and the effects of total UMI counts, percentage of mitochondrial counts and cell cycle ("all" effects; using known G2 and $\mathrm{S}$ phase associated genes ${ }^{56}$ ) regressed out with the Seurat $\mathrm{R}$ package (version 2.3.4). Significantly variable genes $(\mathrm{n}=1164)$ were selected using the "trendVar" function from the $\mathrm{R}$ Bioconductor package Scran (minimum mean log-expression 0.05, BH adjusted p-value < 0.05 ). These genes were used as input for principal component analysis (PCA), and significant PCs ( $\mathrm{n}=33$ ) identified using Seurat ("JackStraw" test, BH adjusted $\mathrm{p}<0.05$ ). These principle components were used as input for alignment with Harmony (version 0.0.0.9, theta $=0$ ). The first 30 Harmony components were used for graph-based clustering as implemented in Seurat ("original" Louvain algorithm, resolution $=0.5$ ). Significant cluster markers were identified using the Seurat "Findmarkers" function (Wilcoxon tests, BH adjusted $\mathrm{p}$ value $<0.05$ ). The tSNE projection (Figure 3a) was computed using the 30 Harmony components and a perplexity of 50. Geneset over-representation analysis of cluster marker genes (Supplementary Fig. 4a) was performed using one-sided Fisher's exact tests (as implemented in the "gsfisher" R package https://github.com/sansomlab/gsfisher) with Biological Process gene sets obtained from the Gene Ontology (GO) database ${ }^{57}$. For this analysis cluster-specific gene universes were defined as those genes expressed in $10 \%$ percent of cells (either within or outside the cluster of interest). Genesets were independently filtered for an odd ratio of $\geq 1.5$ and $n \geq 3$ foreground genes before multiple testing correction (enrichments with a $\mathrm{BH}$ adjusted $\mathrm{p}<0.05$ were considered significant).

\section{Comparison of LPS + anti-IL-10R single-cell RNA-sequencing data from two}

\section{donors.}

The dataset was filtered as for the cross-condition analysis (removing $n=23$ contaminating lymphocytes) and an equal number ( $\mathrm{n}=2280$ ) of cells randomly sub-sampled from each donor for further analysis. Normalisation and scaling (including regression of cell-cycle effects), identification of variable genes ( $\mathrm{n}=849$ ), identification of significant PCs $(\mathrm{n}=35)$ and clustering (resolution=0.6) was performed as described above (no alignment performed). 
Identification and characterisation of gene co-expression modules in the RISK cohort:

RPKM expression values for the RISK cohort ${ }^{20,21}$ were retrieved from GEO (GSE57945), upper-quartile normalised and $\log 2(\mathrm{n}+1)$ transformed. Prior to WGCNA analysis the dataset was filtered to retain $(n=13,850)$ genes that had a transformed expression value $\geq 1.5$ in $>10 \%$ of the patients. The WGCNA R package (version 1.66) was then applied as follows (i) data was cleaned using the "goodSamplesGenes" function (with parameters: minFraction $=0.5$, minNsamples $=4$, minNGenes $=4$, minRelativeWeight $=0.1$, (ii) outlying samples $(\mathrm{n}=11)$ were identified and removed using the "cutreeStatic" function (with parameters: cutHeight=110, minSize=20), (iii) adjacencies calculated with the "adjacency" function (parameters: type $=$ signed_hybrid, power $=5$, $\operatorname{corFnc}=\mathrm{cor}$, corOptions use $=\mathrm{p}$ and method $=$ spearman"), (iv) the topological overall matrix computed with the "TOMsimilarity" function (parameter TOMType=unsigned), (v) a dynamic tree cut performed with function "cutreeDynamic" (parameter deepSplit=2, pamRespectsDendro=FALSE, minClusterSize $=30$ ) and (vi) modules merged with the "mergeCloseModules" function (parameter cutHeight=0.25). Genes assigned to modules were subject to geneset over-representation analysis as described for the single-cell RNA-sequencing analysis with gene categories obtained from the Gene Ontology (GO) database ${ }^{58}$, KEGG pathways ${ }^{59}$ and sets of cell type marker genes $(\mathrm{xCell})^{60}$. Indicative monikers for the modules were manually assigned based on genes with high module membership $(\mathrm{r}>$ 0.8 with the module eigengene) as well as GO category, KEGG pathway and xCell marker enrichments (see Suplementary Table 4). The overlap of the identified WGCNA modules with IBD GWAS associated genes was performed using the associations reported by Ellinghaus et. $a l^{51}$ (Ellinghaus Supplementary Table 3a, $\mathrm{n}=156$ genes) or by de Lange et. $a l^{5}$ (de Lange Supplementary Table 2). The associated genes from de Lange et. al. were conservatively filtered to retain only "implicated" genes or genes that originate from single-gene loci ( $\mathrm{n}=89$ genes, 48 of which overlap with the Ellinghaus et. al. set).

Identification and characterisation of an IL-10-responsive monocyte gene signature:

The IL-10 regulated inflammatory monocyte gene signature (Figure 5e) was constructed from (i) genes that showed $\geq 3$-fold higher expression in at least one of the three LPS + aIL10R clusters than was found in any of the unstimulated or LPS-stimulated clusters (single-cell 
RNA-sequencing analysis, Figure 3a), (ii) genes that showed significantly higher expression in the $\mathrm{CD} 14^{+}$positive PBMC fraction upon with anti-IL-10R + LPS stimulation versus LPS stimulation alone ( $\mathrm{n}=1$, IL-1B, Supplementary Fig. 5), and (iii) two genes from the literature: CD14, a well-established monocyte type cell marker and OSM which is known to be expressed by inflammatory monocytes in human IBD and to drive colitis in the $H h+$ anti-IL-10R model ${ }^{18}$. The predictive ability of genes in the IL-10 regulated inflammatory monocyte signature was investigated in RNA-seq data from the RISK cohort and Affymetrix microarray data from the Janssen $^{22}$ (UC-cohort GSE12251, Figure 5f). The UC-cohort GSE12251 includes data from patients with active UC that had a total Mayo score between 6-12 and an endoscopic sub-score of at least 2. The response to infliximab was defined as endoscopic and histologic healing in patients that underwent a second flex sigmoidoscopy with rectal biopsies 4 weeks after the first infliximab infusion in case of a single infusion and at 6 weeks if they received a loading dose of infliximab at weeks 0, 2 and 6. Microarray datasets from the Janssen (GSE12251) and Arijs $(G S E 16879)^{23}$ cohorts were RMA normalised (R Bioconductor package "oligo") and annotated with data from the R Bioconductor "hgu133plus2.db" package (signals from probes mapping to the same gene symbol were averaged). Predictive ability was assessed by computation of area under the precision recall curve (AUPRC) using the R PRROC library.

\section{Real-time PCR:}

Real-time PCRs were performed in 96-well plates using the PrecisionPLUS qPCR Mater Mix (Primer Design) and the CFX96 Touch Real-Time PCR Detection System machine (BIORAD). The expression of transcripts was normalized to expression of Large Ribosomal Protein $(R P L P O)$. Data analysis was performed using the Cycles threshold $(\triangle \Delta \mathrm{Ct})$ method and expressed as mRNA relative expression $\Delta \Delta \mathrm{Ct}$. The following TaqMan probes (Applied Biosystems) were used for qPCR analysis: IL23A (Hs00900828_g1), IFNG (Hs00989291_m1), RPLPO(Hs99999902_m1).

\section{Gene array expression and statistical analysis:}

Background correction and quantile normalization of the gene expression data obtained from the Affymetrix Human Transcriptome Array 2.0 (HTA2) platform were performed by the RMA method ${ }^{16}$. Each gene's expression was defined at the level of the "transcript cluster", which is the collection all probesets on the HTA2 platform that are located within a gene's annotated position in the genome. These gene positions were defined by the Affymetrix 
NetAffxTM NA34 release, which is based on the GRCh37 human reference genome. Differential expression at the gene-level was performed using the empirical Bayes method implemented in LIMMA ${ }^{61}$ controlling for donor in the model. Differential expression between a given stimulation vs. PBMC control contrast was considered at a Benjamini-Hochberg adjusted $p$-value $<0.05$ and absolute fold change $>2$. A heatmap was produced using the heatmap.2 function from the gplots package (R-3.4.2) to visualise the union of genes that were regulated in each stimulation vs. PBMC control contrast.

\section{Mathematical modelling of cytokine interactions.}

We define a system of ordinary differential equations of the form $\frac{d x_{i}}{d t}=s_{i} \prod_{u}\left(1+\alpha_{u, i} x_{u}\right) \prod_{v}\left(1+\beta_{v, i} x_{v}\right)$, with $x_{i}$ the concentration of TNF, IL-1 $\alpha$, IL-1 $\beta$, IL6 , IL-10 or IL-23 over time, $s_{i}$ the contribution of LPS, and $\alpha_{u, i}\left(\beta_{u, i}\right)$ the positive (negative) effect of cytokine $u$ on the production rate of cytokine $i$. With additional time and/or dose dependent data, the model could be extended by including saturation of cytokine production (e.g. using Michaelis-Menten or Hill functions) or cytokine degradation. By minimizing the $\log$ likelihood, we fit the right-hand side of the equations to 1750 experimental data points, representing cytokine production rates by monocytes 16 hours after LPS stimulation. These rates were determined by intracellular flow cytometry in PBMC derived from healthy individuals, in the presence or absence of anti-IL-10R, and TNF, IL-1 $\beta$, IL-6, IL-10, IL23, IFN $\gamma$, anti-IFN $\gamma$, anti-IFNR1, anti-IL-1 $\alpha$, anti-IL-1 $\beta$, anti-IL-1R1, anti-IL-6R, or antiTNF ( $n=3-17)$. The frequency of cytokine (i.e. TNF, IL-1 $\alpha$, IL-1 $\beta$, IL-6, IL-10 or IL23) producing live $\mathrm{CD} 14^{+}$cells multiplied by the mean fluorescence intensity of the respective cytokine producing cell population was taken as a measure of cytokine production rate. All possible network configurations using a set of edges representing significant (paired Wilcoxon test, $\mathrm{p} \leq 0.05$ ) direct cytokine interactions derived from this dataset were considered, and for each number of edges, an optimal model configuration was found. We did not model all $2^{31}-1$ possible configurations explicitly, as the vast majority of configurations could be logically excluded based on a small subset of network configuration fits. It was found that all optimal models were nested, i.e. the list of optimal models can be obtained by iteratively adding edges to the model. As additional edges will always improve the model fit, we use the Akaike Information Criterion (AIC) to identify the fourteen-edge model as the model with an optimal balance between edge number and model fit. For two nested models that differ one edge, the AIC is equivalent to a likelihood ratio test $(\mathrm{LRT}$, alpha $=0.16)$ with one degree of 
freedom. Fitting and parameter identifiability analysis of the fourteen-edge model was done in the Matlab based modelling environment 'Data2Dynamics', using a deterministic trust-region approach combined with a multi-start strategy; data2dynamics.org ${ }^{62}$.

Resources for data visualization:

Gene and protein networks were visualized using Cytoscape 3.6.1: http://www.cytoscape.org $/{ }^{63}$.

Heatmaps for gene expression data visualisation were generated using the GENE-E or Morpheus tool from the Broadinstitute: http://www.broadinstitute.org/cancer/software/ GENE-E/; https://software.broadinstitute.org/morpheus/. 


\section{SUPPLEMENTARY REFERENCES}

50. Korsunsky I, Millard N, Fan J, et al. Fast, sensitive and accurate integration of singlecell data with Harmony. Nat Methods 2019;16:1289-1296.

51. Ellinghaus D, Jostins L, Spain SL, et al. Analysis of five chronic inflammatory diseases identifies 27 new associations and highlights disease-specific patterns at shared loci. Nat Genet 2016;48:510-8.

52. Schulthess J, Pandey S, Capitani M, et al. The Short Chain Fatty Acid Butyrate Imprints an Antimicrobial Program in Macrophages. Immunity 2019;50:432-445 e7.

53. Sonnenborn U. Escherichia coli strain Nissle 1917-from bench to bedside and back: history of a special Escherichia coli strain with probiotic properties. FEMS Microbiol Lett 2016;363.

54. van der Maaten L, Hinton G. Visualizing non-metric similarities in multiple maps. Machine Learning 2012;87:33-55.

55. Wallach I, Lilien R. The protein-small-molecule database, a non-redundant structural resource for the analysis of protein-ligand binding. Bioinformatics 2009;25:615-20.

56. Dominguez D, Tsai YH, Gomez N, et al. A high-resolution transcriptome map of cell cycle reveals novel connections between periodic genes and cancer. Cell Res 2016;26:946-62.

57. Ashburner M, Ball CA, Blake JA, et al. Gene ontology: tool for the unification of biology. The Gene Ontology Consortium. Nat Genet 2000;25:25-9.

58. Harris MA, Clark J, Ireland A, et al. The Gene Ontology (GO) database and informatics resource. Nucleic Acids Res 2004;32:D258-61.

59. Kanehisa M, Furumichi M, Tanabe M, et al. KEGG: new perspectives on genomes, pathways, diseases and drugs. Nucleic Acids Res 2017;45:D353-D361.

60. Aran $\mathrm{D}, \mathrm{Hu} \mathrm{Z}$, Butte AJ. xCell: digitally portraying the tissue cellular heterogeneity landscape. Genome Biol 2017;18:220.

61. Ritchie ME, Phipson B, Wu D, et al. limma powers differential expression analyses for RNA-sequencing and microarray studies. Nucleic Acids Res 2015;43:e47.

62. Raue A, Steiert B, Schelker M, et al. Data2Dynamics: a modeling environment tailored to parameter estimation in dynamical systems. Bioinformatics 2015;31:3558-60.

63. Shannon P, Markiel A, Ozier O, et al. Cytoscape: a software environment for integrated models of biomolecular interaction networks. Genome Res 2003;13:2498-504. 


\section{Figure 1}

A

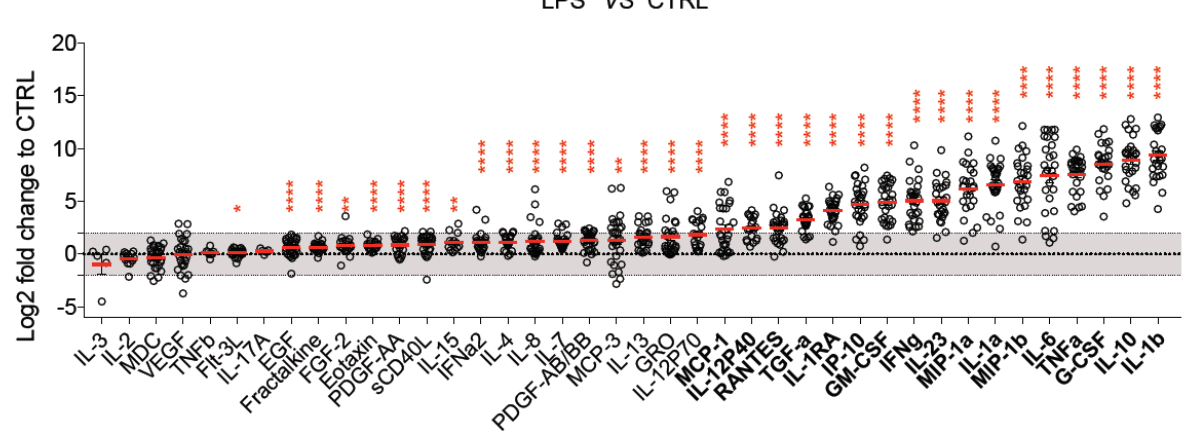

LPS+ $\alpha$ IL-10R VS LPS
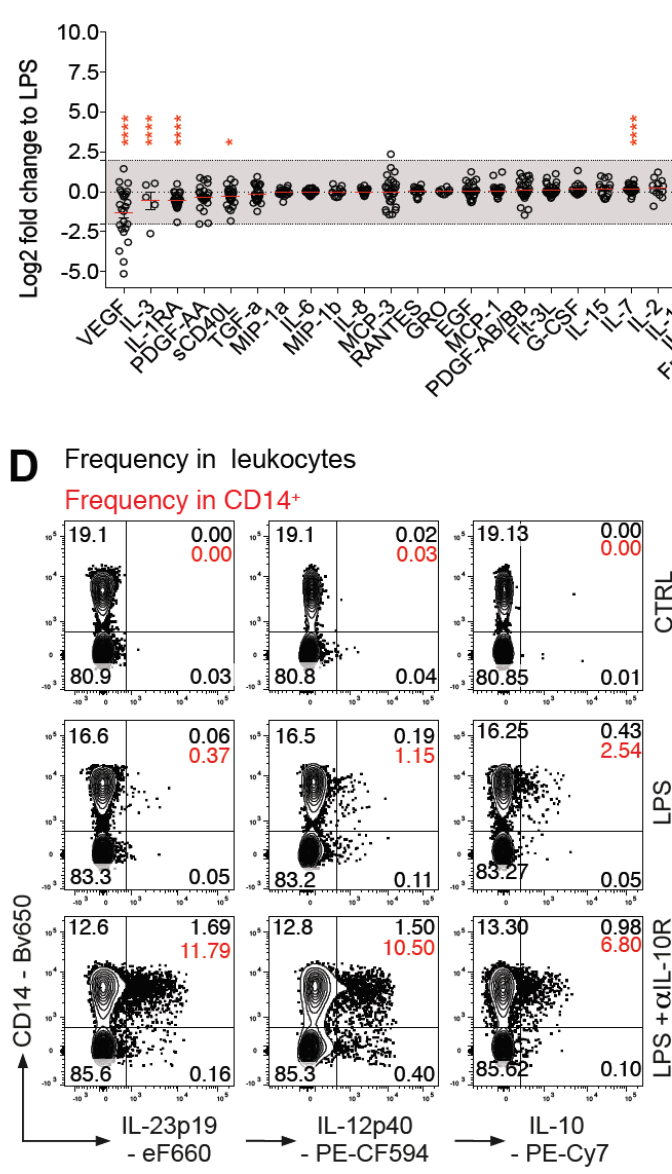

E $\square \mathrm{CD} 14^{+} \square \mathrm{CD}^{-} 4^{-}$

IL-12p $40^{+} \mathrm{IL}-23 \mathrm{p} 19^{+} \quad \mathrm{IL}-10^{+}$
C

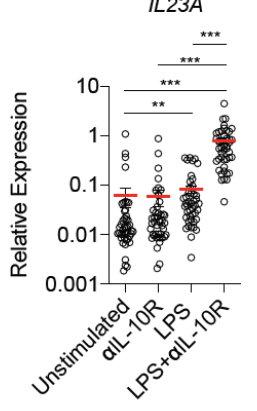

B

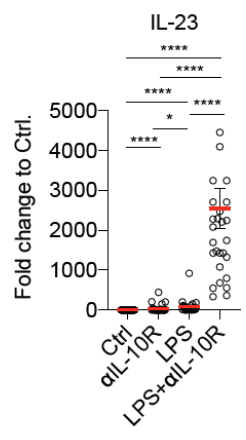

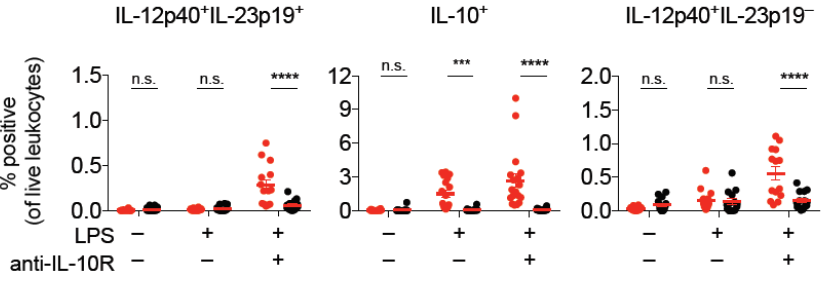

$\mathbf{F}$

$\mathrm{CD} 14^{+} \mathrm{IL}-12 \mathrm{p} 40^{+} \mathrm{IL}-23 \mathrm{p} 19^{+} \quad \mathrm{CD} 14^{+} \mathrm{IL}-10^{+} \quad \mathrm{CD} 14^{+} \mathrm{IL}-12 \mathrm{p} 40^{+} \mathrm{IL}-23 \mathrm{p} 19^{-}$

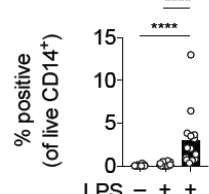

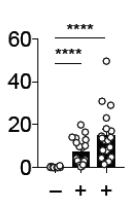


Figure 1: IL-10 regulates $I L 23 A$ transcription and IL-23 protein secretion in a subset of monocytes from patients with IBD. (A) Analysis of PBMC culture supernatants collected after 16 hours stimulation with LPS +/- IL-10R blocking antibodies expressed as $\log 2$ fold change to unstimulated PBMC (CTRL) or LPS-stimulated PBMC ( $\mathrm{n}=28)$. Mean +/- SEM; Wilcoxon test, BH-adjusted p-values. (B) IL-23 protein concentrations in culture supernatants expressed as fold change to unstimulated PBMC $(\mathrm{n}=28)$. Mean $+/-$ SEM; Friedman test, BHadjusted p-values. (C) RT-qPCR analysis of relative $I L 23 A$ expression in PBMC $(\mathrm{n}=45)$ following 16 hours stimulation. Mean +/- SEM; Kruskal-Wallis test, BH-adjusted p-values. (D) Contour plot presentation of IL-23p19-, IL-12p40- and IL-10-producing live leukocytes and CD14 surface expression measured at 16 hours post stimulation in PBMC. (E) Summary of frequencies of IL-12p40 IL-23p $19^{+}$, IL- $10^{+}$and IL-12p $40^{+} \mathrm{IL}-23 \mathrm{p} 19^{-} \mathrm{CD} 14^{+}$and CD14 cells in total live leukocytes $(\mathrm{n}=18)$. Mean +/- SEM; Mann-Whitney test. (F) Summary of frequencies of IL-12p $40^{+} \mathrm{IL}-23 \mathrm{p} 19^{+}, \mathrm{IL}_{-10} 0^{+}$and IL-12p40 ${ }^{+} \mathrm{IL}-23 \mathrm{p} 19^{-}$of CD $14^{+}$cells $(\mathrm{n}=18)$. Mean +/- SEM; Mann-Whitney test. 
bioRxiv preprint doi: https://doi.org/10.1101/719492; this version posted January 31, 2020. The copyright holder for this preprint (which was not certified by peer review) is the author/funder, who has granted bioRxiv a license to display the preprint in perpetuity. It is made available under aCC-BY-NC-ND 4.0 International license.

Figure 2

A

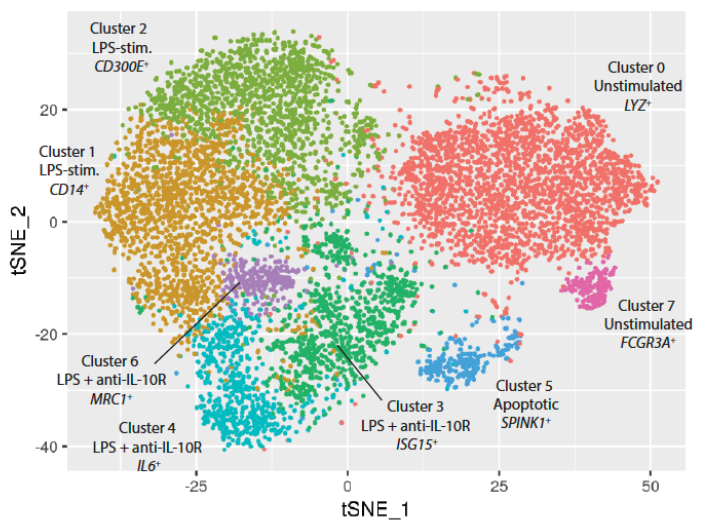

B
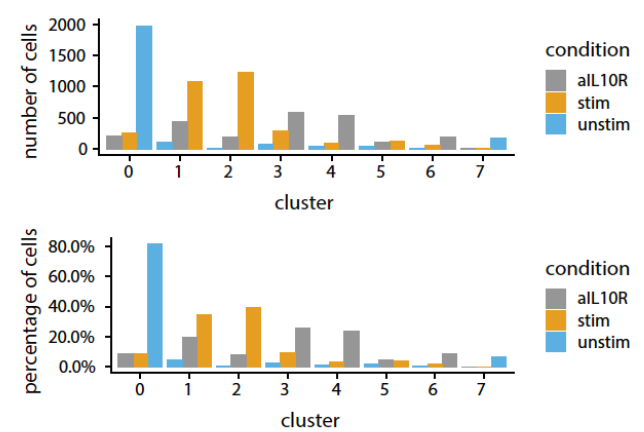

C
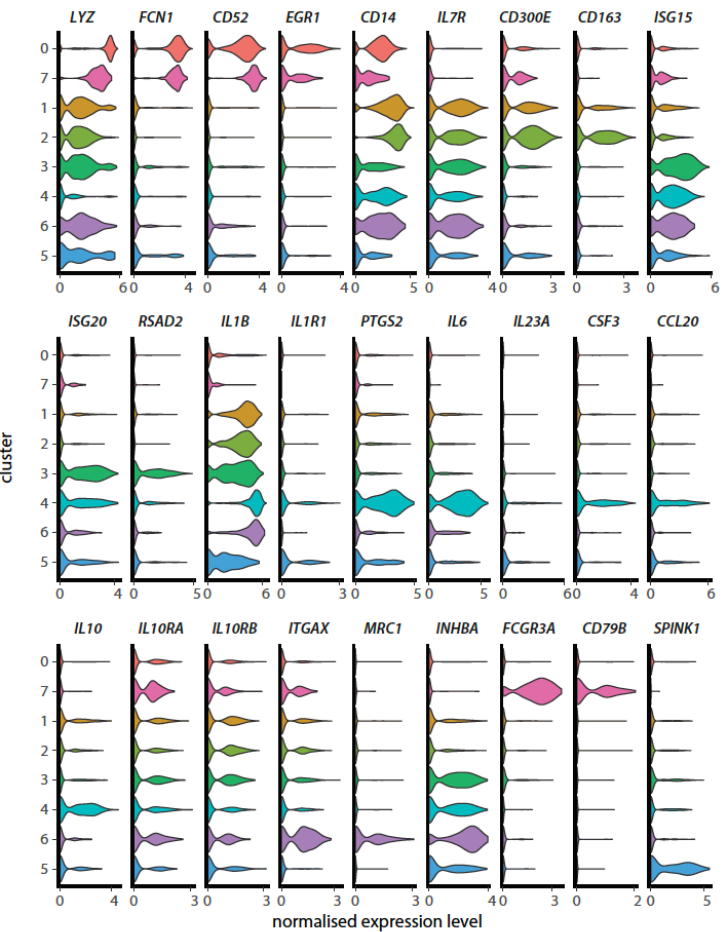

D
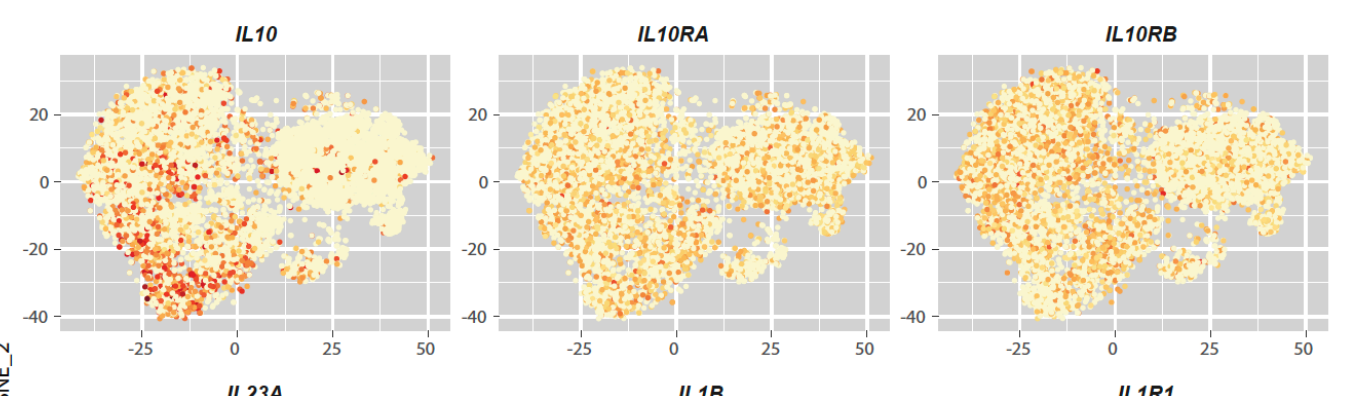

$\log$

normalised

崩

IL23A
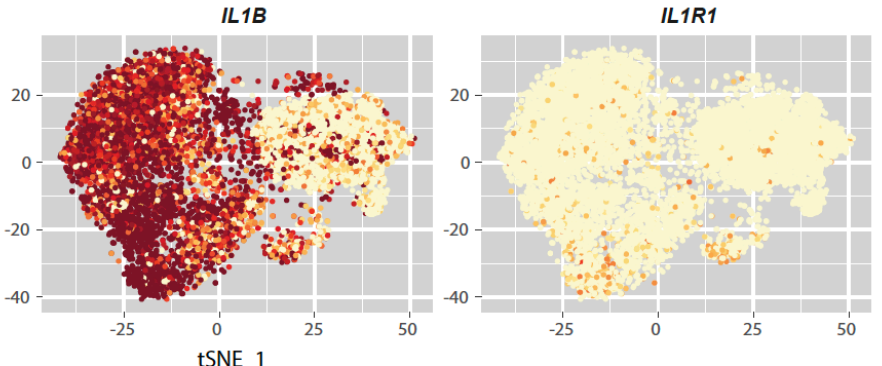

counts

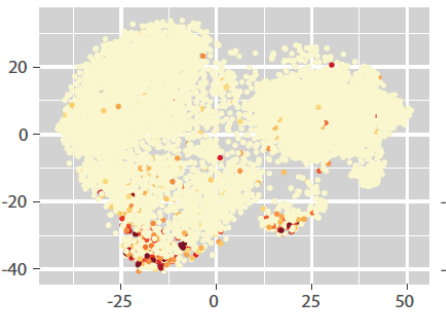

tSNE_1 
Figure 2: Single cell RNA-sequencing identifies subsets of inflammatory monocyte.

(A) The tSNE plot shows the sub-populations of unstimulated, LPS-stimulated and combined LPS and anti-IL-10R stimulated monocytes that were identified by a graph-based clustering approach following cross-condition alignment with Harmony ${ }^{50}$. (B) The bar plots show the number and frequency of cells from the three stimulation conditions in each of the identified clusters. (C) The violin plots showing expression (x-axis) of genes characteristic of the identified monocyte clusters (y-axis). (D) Expression of IL10, IL10RA, IL10RB, IL23A, IL1B and ILIRI across the single monocytes according to figure (A). 
bioRxiv preprint doi: https://doi.org/10.1101/719492; this version posted January 31, 2020. The copyright holder for this preprint (which was not certified by peer review) is the author/funder, who has granted bioRxiv a license to display the preprint in perpetuity. It is made available under aCC-BY-NC-ND 4.0 International license.

\section{Figure 3}
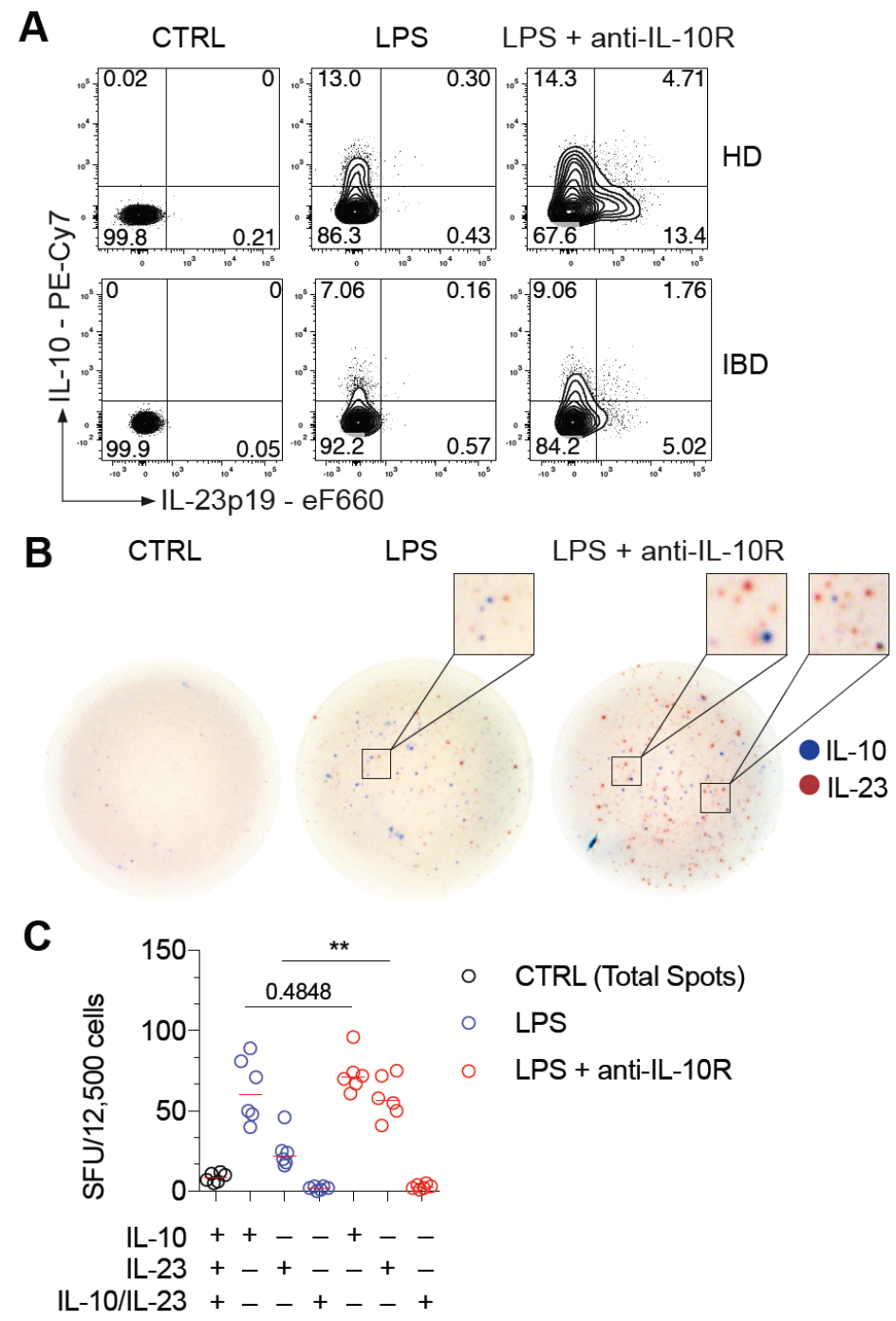
Figure 3: The monocyte response to $P R R$ stimulation is heterogeneous revealing a paracrine mechanism of IL-10-depedent regulation of IL-23 production. (A) Representative contour plot presentation showing IL-23p $19^{+}$and IL- $10^{+}$frequencies in monocytes derived from a healthy donor and a patient with IBD at 16 hours post stimulation. (B) Representative dual-colour ELISpot images showing non-stimulated, LPS-stimulated and combined LPS and anti-IL-10R-stimulated monocytes IL-10 secretion (blue) and IL-12p40 IL$23 \mathrm{p} 19^{+}$secretion (red). (C) Summary of dual-colour ELISpot measurements from 3 independent experiments $(\mathrm{n}=6$, Mean +/- SEM; Mann-Whitney test). 
bioRxiv preprint doi: https://doi.org/10.1101/719492; this version posted January 31, 2020. The copyright holder for this preprint (which

was not certified by peer review) is the author/funder, who has granted bioRxiv a license to display the preprint in perpetuity. It is made available under aCC-BY-NC-ND 4.0 International license.

Figure 4

A

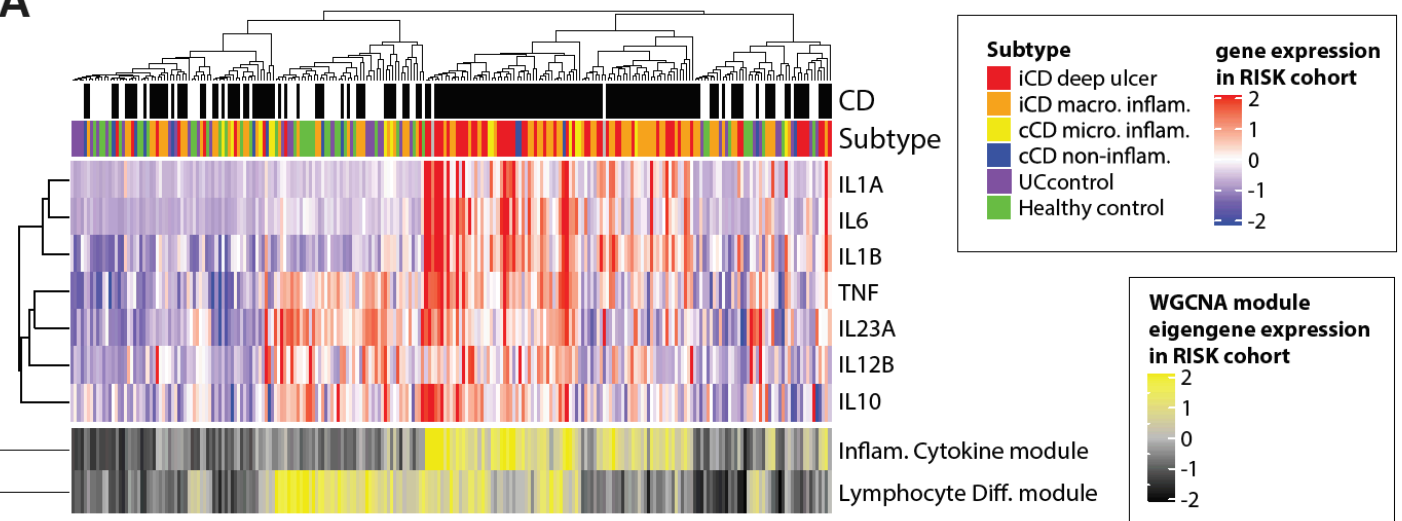

B

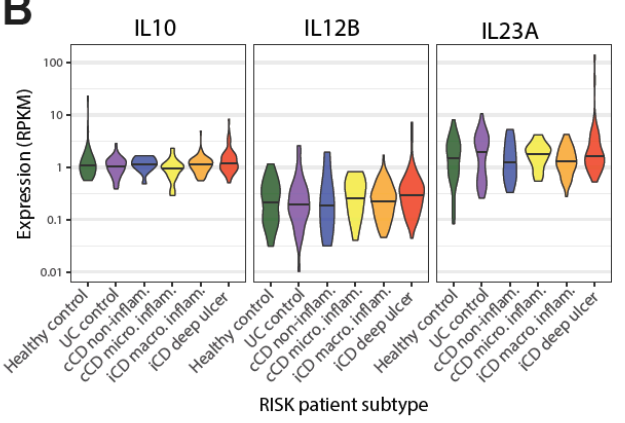

C

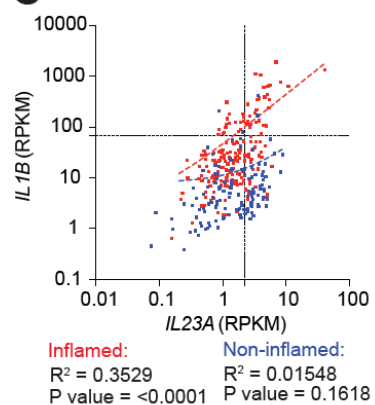

D

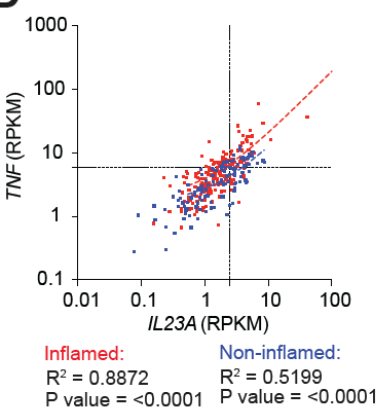

E

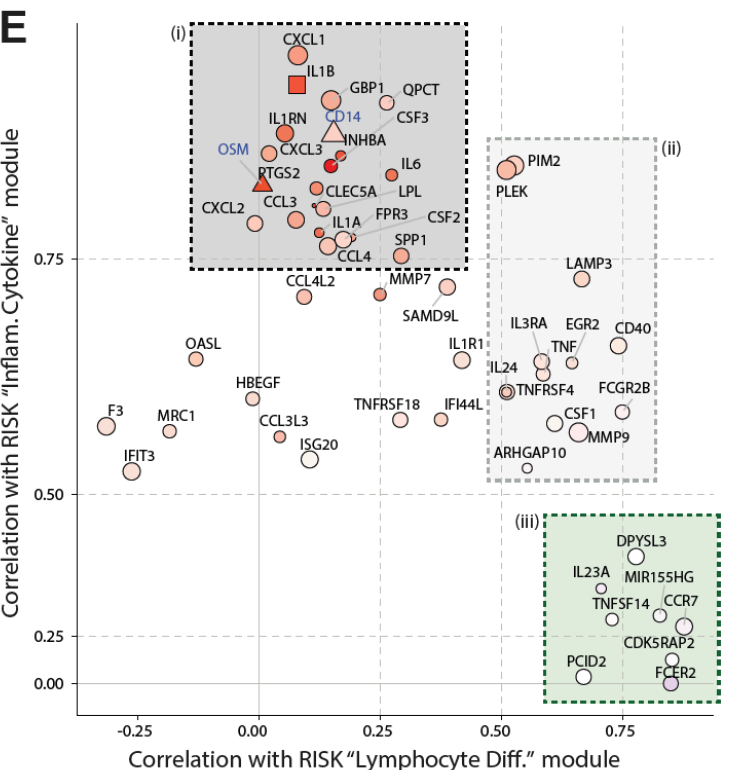

Correlation with RISK“Lymphocyte Diff." module
$\mathbf{F}$
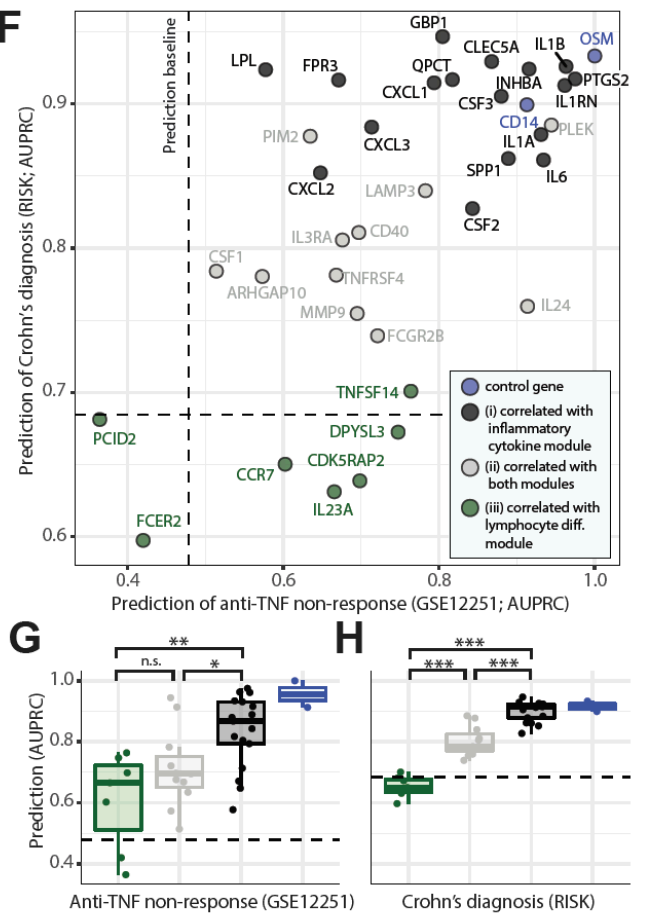
Figure 4: An IL-10-regulated inflammatory monocyte gene signature informs IL-23 and IL-1 targeting therapeutic approaches in inflammatory bowel disease. (A) Patients of the RISK cohort (diagnosis and subtype as shown in top panels) were clustered according to the expression of 22 modules of co-expressed genes (see Supplementary Figure 5A). The upper heatmap shows expression of key cytokines across the cohort. The lower panel shows expression of the eigen-genes of two of the identified modules of co-expressed genes. (B) The expression of $I L 10, I L 12 B$ and $I L 23 A$ within the different patient strata of the RISK cohort. (C and D) Correlation of $I L 23 A$ with $I L 1 B(C)$ and $I L 23 A$ with $T N F(D)$ in the inflamed (red) and non-inflamed (blue) patient biopsies of the RISK cohort. (E) Correlation of genes specific to LPS and anti-IL-10R stimulated monocytes with the "inflammatory cytokine" and "lymphocyte differentiation" gene modules in the RISK cohort data identifies three subsets (shaded (i) black, (ii) grey and (iii) green boxes). (F) Assessment of the ability of the identified monocyte genes to predict anti-TNF non-response (x-axis, GSE12251) and diagnosis of Crohn's (y-axis, RISK cohort). The dashed lines indicate random classifier performance. (G and $\mathbf{H}$ ): comparison of the ability of the identified subsets of monocyte genes to predict TNF non-response in the Janssen cohort and diagnosis of CD in the RISK cohort (Wilcoxon tests, colours as shown in panels (E) and (F)). AUPRC: area under precision recall curve. 
bioRxiv preprint doi: https://doi.org/10.1101/719492; this version posted January 31, 2020. The copyright holder for this preprint (which was not certified by peer review) is the author/funder, who has granted bioRxiv a license to display the preprint in perpetuity. It is made available under aCC-BY-NC-ND 4.0 International license.

\section{Figure 5}

A

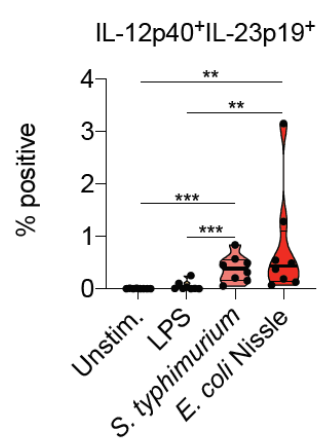

C $\mathrm{CD}^{+} 4^{+}$
monocytes

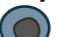

Stimulation with LPS or heat-killed

1

Wash and re-stimulation with IL-10

Analysis

of STAT3

phosphorylation
B

Control LPS

S. typhimurium $\quad$ E. coli Nissle

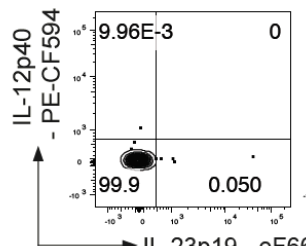

$\rightarrow$ IL-23p19 - eF660
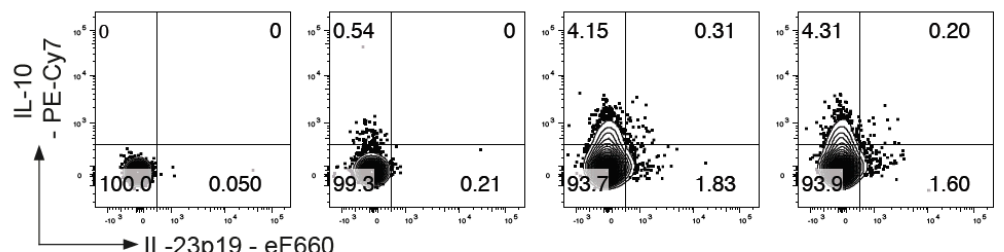

E

pSTAT3
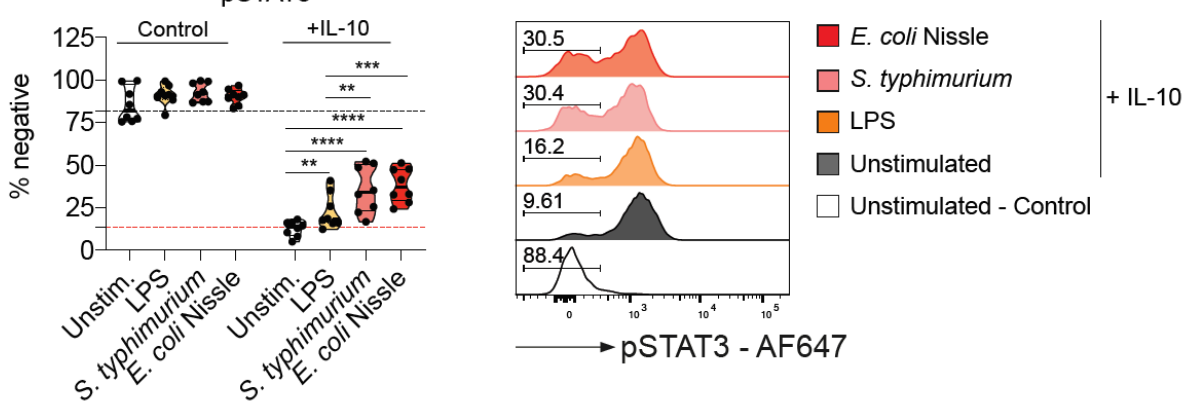
Figure 5: Monocyte uptake of whole bacteria causes IL-10 resistance and IL-23 secretion.

(A) Frequencies of IL-12p $40^{+} \mathrm{IL}-23 \mathrm{p} 19^{+}$live $\mathrm{CD} 14^{+}$at 16 hours following stimulation $(\mathrm{n}=8$, Mean +/- SEM; Mann-Whitney test). (B) Dot plots showing IL-12p40, IL-23p19 and IL-10 in live $\mathrm{CD} 14^{+}$monocytes from a healthy donor. (C) Scheme for the assessment of monocyte IL10 responsiveness. (D) Frequencies of phospho-STAT3- live monocytes without cytokine stimulation (Control) and following 15 minutes IL-10 (50 $\mathrm{ng} / \mu \mathrm{l})$ stimulation $(\mathrm{n}=8$, Mean $+/-$ SEM; Mann-Whitney test). (E) Representative histograms showing phosphorylation of STAT3 in non-treated (Control) or IL-10-treated (+IL-10) live monocytes. Percentages of IL-10 stimulation-resistant monocytes are indicated. 
bioRxiv preprint doi: https://doi.org/10.1101/719492; this version posted January 31, 2020. The copyright holder for this preprint (which was not certified by peer review) is the author/funder, who has granted bioRxiv a license to display the preprint in perpetuity. It is made available under aCC-BY-NC-ND 4.0 International license.

\section{Figure 6}

A

Fold change to LPS/LPS + alL-10R

IL-12p40+IL-23p $19^{+}$

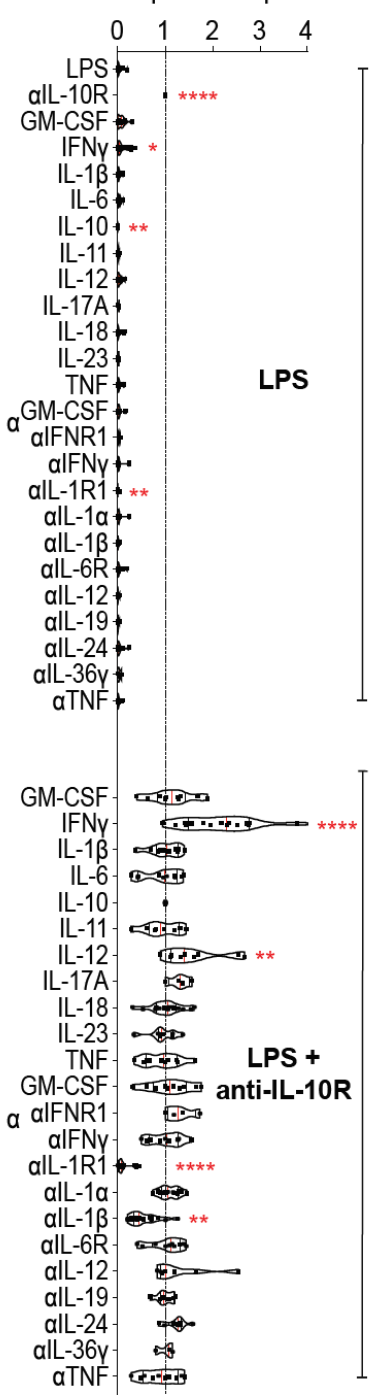

B
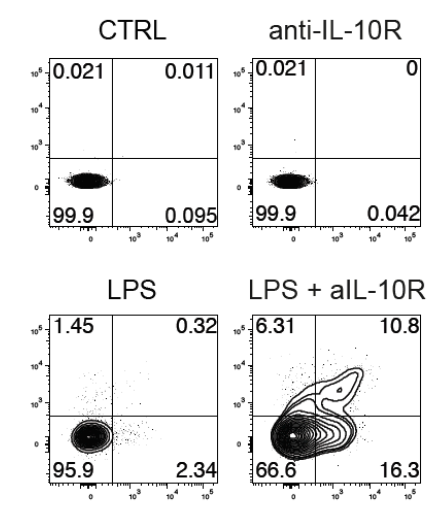

LPS + alL1R1

LPS + alL-10R

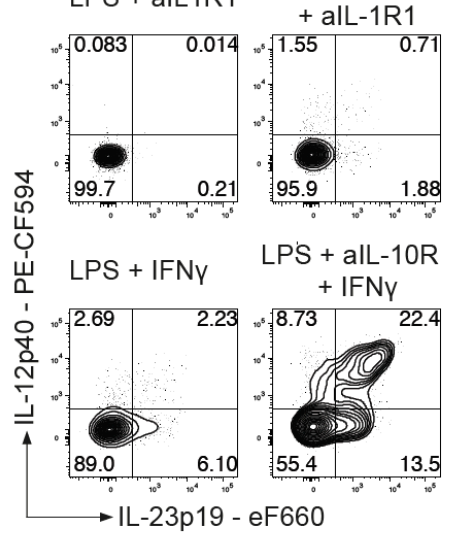

D

$\begin{array}{ll}\text { IL-23+ Inflammatory } & \text { IFN-induced } \\ \text { Monocytes } & \text { Monocytes }\end{array}$

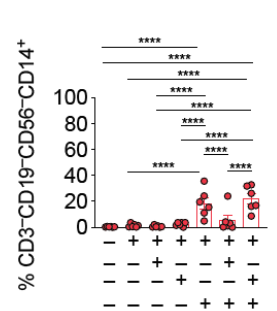

C
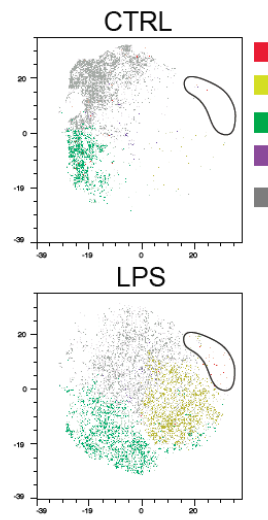

LPS + alL1R1

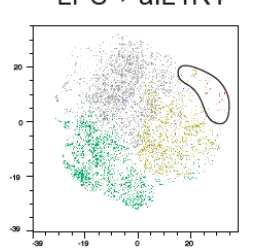

LPS + IFNY

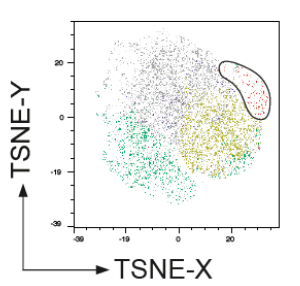

Microbicidial Monocytes

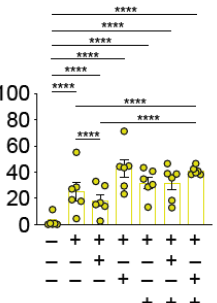

IL-23+ Inflammatory Monocytes IFN-induced Monocytes

Microbicidal Monocytes

Apoptotic Monocytes

Ungated Monocytes

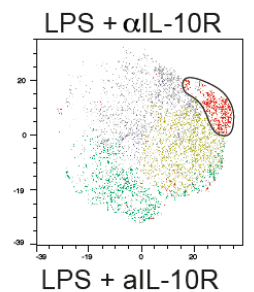

LPS + alL-10R
+ alL-1R1

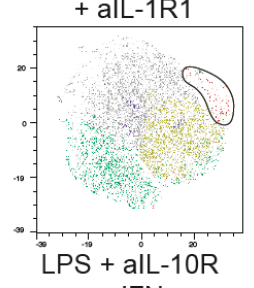

+ IFNy

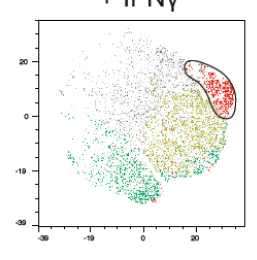

Apoptotic Monocytes
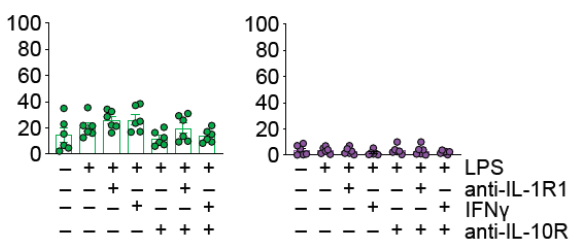
Figure 6: IL-1 $\alpha$ and IL-1ß signalling are essential for monocyte IL-23 production. PBMC from healthy donors $(n=4-20)$ were stimulated for 16 hours with combinations of LPS and $\alpha \mathrm{IL}-10 \mathrm{R}$ in the presence of indicated exogenous human recombinant cytokine (all $10 \mathrm{ng} / \mathrm{ml}$ ), and/or cytokine/cytokine receptor blockade (all antibodies $10 \mu \mathrm{g} / \mathrm{ml}$ ). (A) Frequencies of IL$12 \mathrm{p} 40^{+} \mathrm{IL}-23 \mathrm{p} 19^{+}$live CD14 $4^{+}$monocytes (Wilcoxon test; 95\% CI). (B) Representative dot plot showing intracellular IL-12p40 and IL-23p19 according to (A). (C) tSNE presentation of IL23p19, CCL20, HLA-DR, IDO-1, CCL2, S100A8, RPS6 and SPINK-1 expression in live $\mathrm{CD} 14^{+} \mathrm{CD} 3^{-} \mathrm{CD} 19^{-} \mathrm{CD} 56^{-}$-gated monocytes. Analysis of 3 healthy donors are shown as overlay. (D) Frequencies of monocyte clusters across stimulations based on cluster-specifying protein expression ( $\mathrm{n}=6$; one way ANOVA after BH correction). 
bioRxiv preprint doi: https://doi.org/10.1101/719492; this version posted January 31, 2020. The copyright holder for this preprint (which was not certified by peer review) is the author/funder, who has granted bioRxiv a license to display the preprint in perpetuity. It is made available under aCC-BY-NC-ND 4.0 International license.

Figure 7

A
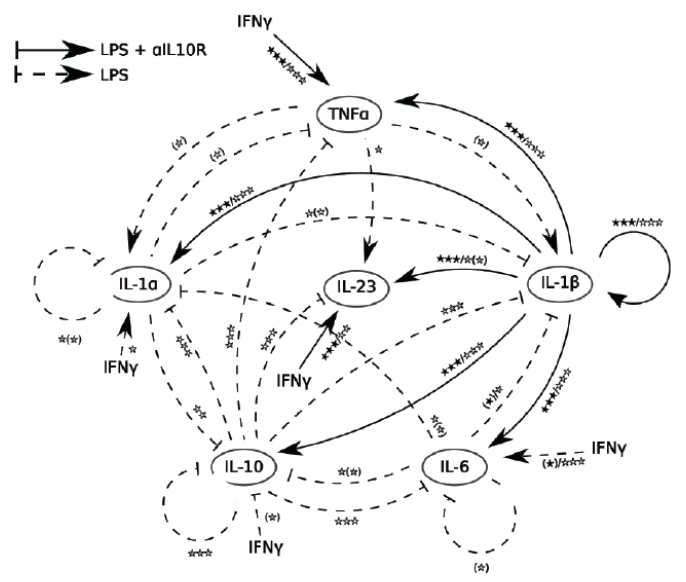

B
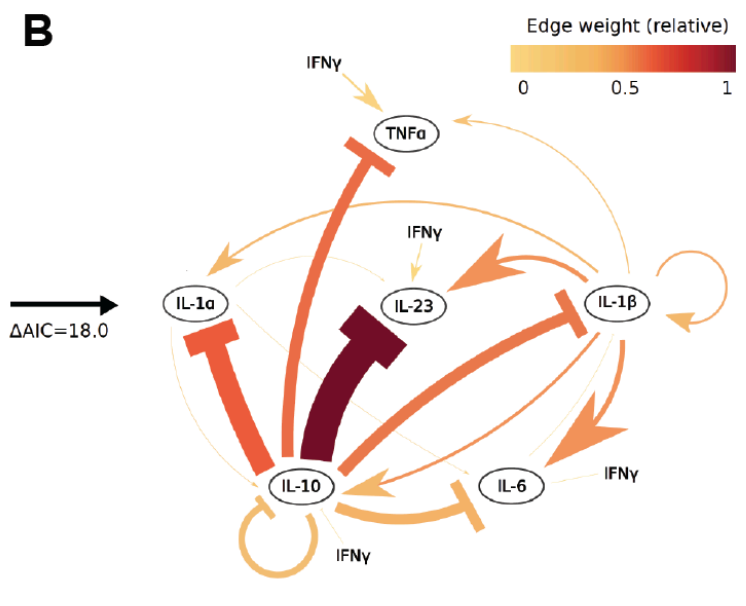

C ${\text { CD } 14^{+} \text {pStAT3 }}$

$\mathrm{CD}^{+}$pSTAT3
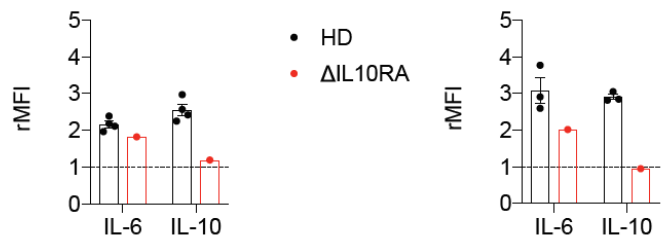

- HD

- $\triangle \mathrm{IL} 10 \mathrm{RB}$

D

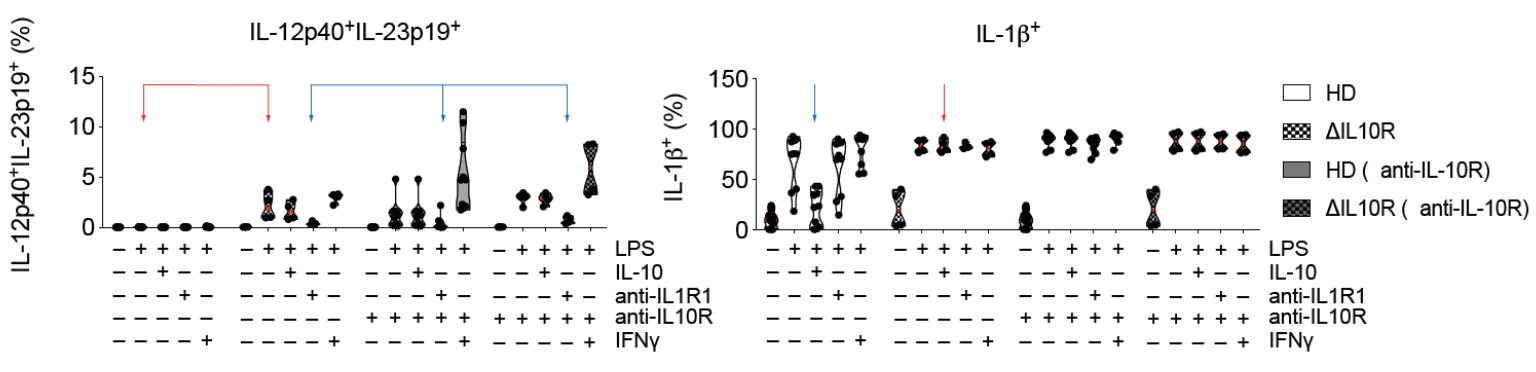


Figure 7: A mathematical model describing the modulation of monocyte IL-23 expression and analysis of monocyte IL-23 responses in patients with LOF in IL-10R1 and IL-10R2.

(A) The extensive model represents the effects of the addition or blockade of cytokines in a PBMC culture in the presence of LPS or LPS and anti-IL-10R. Differences of cytokine addition or blockade in LPS stimulated samples (dashed arrows), in LPS and anti-IL-10R-stimulated samples (solid arrows), and in LPS and anti-IL-10R-stimulated and anti-IL-1 $\beta$ treated conditions (dotted arrows). Nominal effects with $\mathrm{p}>0.05$ after false discovery rate (Benjamini \& Hochberg) correction are shown in parenthesis. (B) A reduced complexity model was established by focusing on informative cytokine interactions. Edge weights are defined as the relative contribution to model fit and are dependent on the network configuration considered. The edges of the twenty-edge model have been coloured based on their weight. (C) Analysis of STAT3 phosphorylation following IL-6 or IL-10 stimulation in a patient with a loss of function variant in the gene coding for IL10RA (p.Y167C, left) and a patient with a loss of function variant in the gene coding for IL10RB (p.R117H, right). (D) Frequencies of IL$12 \mathrm{p} 40^{+} \mathrm{IL}-23 \mathrm{p} 19^{+}$and IL-1 $\beta^{+}$monocytes in PBMC from healthy donors and patients with IL10R variants following 16 hours stimulation with combinations of LPS (200 ng/ml), IL-10 (10 $\mathrm{ng} / \mathrm{ml})$, anti-IL-10R (10 $\mu \mathrm{g} / \mathrm{ml})$, anti-IL-1R1 $(10 \mu \mathrm{g} / \mathrm{ml})$ and IFN- $\gamma(10 \mathrm{ng} / \mathrm{ml})$. 
bioRxiv preprint doi: https://doi.org/10.1101/719492; this version posted January 31, 2020. The copyright holder for this preprint (which was not certified by peer review) is the author/funder, who has granted bioRxiv a license to display the preprint in perpetuity. It is made available under aCC-BY-NC-ND 4.0 International license.

\section{Supplementary Figure 1}

A

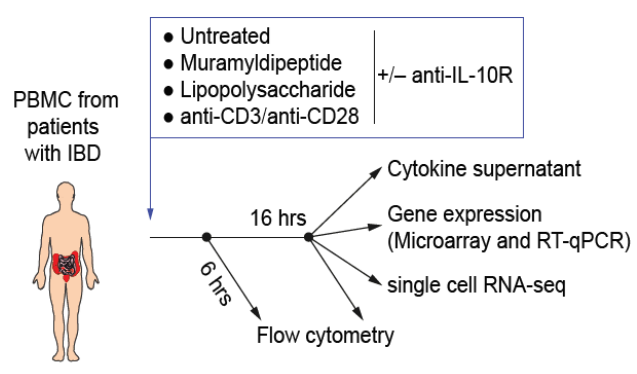

B

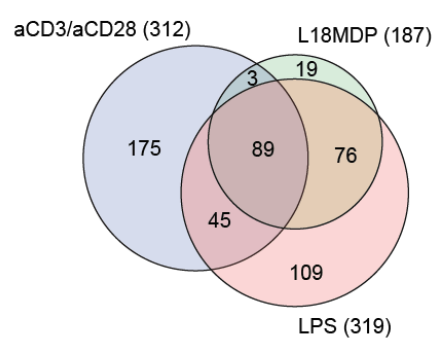

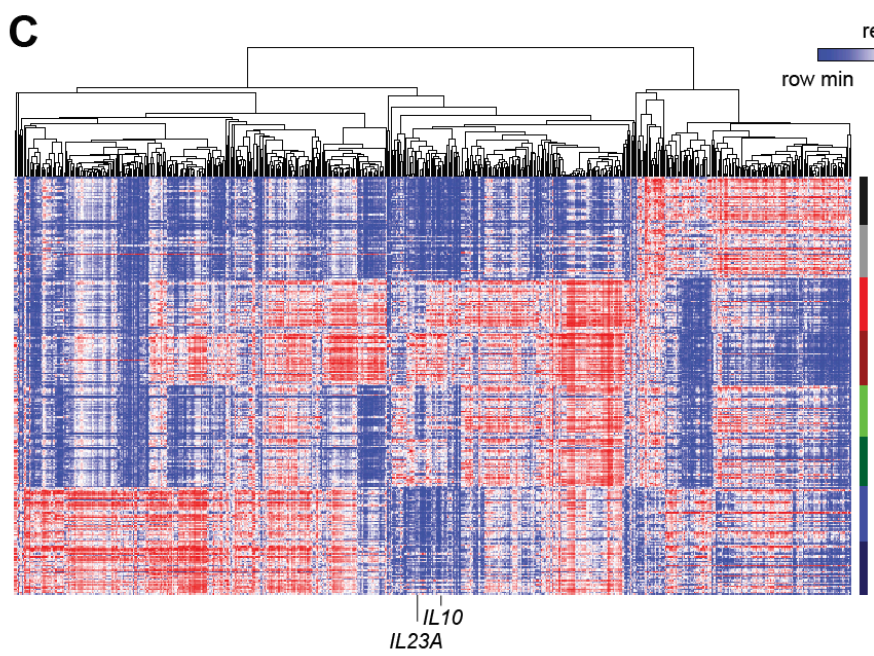

D

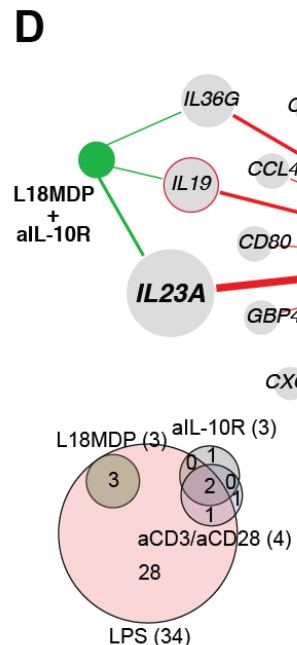

LPS (34)

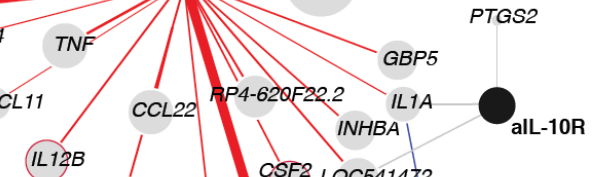

GBP1 IL24 CSF2 LOC541472

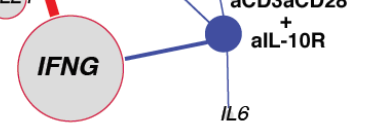

E

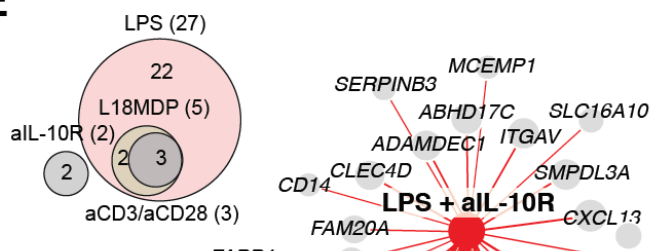

PTGS2

$\mathrm{aCD} 3 / \mathrm{aCD} 28+\mathrm{alL}-10 \mathrm{R}$

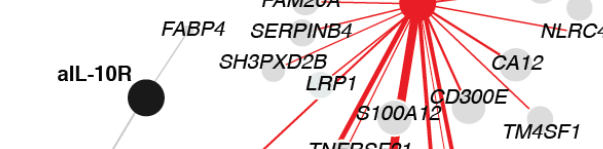

relative

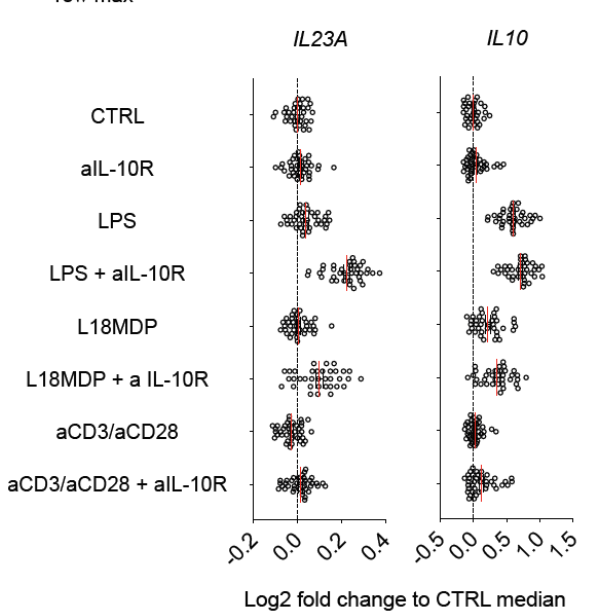

L18MDP (187)

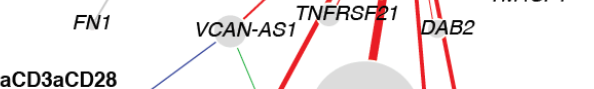

alt-10R

CD163
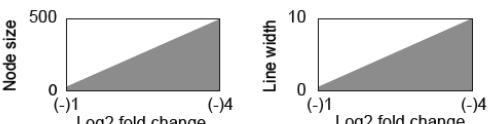

L18MDP + alL-10R

GWAS-based and fine mapped association with IBD 
Supplementary Figure 1: (A) Graphical illustration of ex vivo PBMC stimulations and experimental conditions. (B) Venn-diagram of differentially regulated genes in the three stimulation conditions (LPS, L18MDP, and $\alpha \mathrm{CD} 3 / \alpha \mathrm{CD} 28$ coated beads). (C) Microarray analysis of patients with IBD ( $n=41$; Supplementary Table 1) PBMC samples under diverse stimulation conditions. The heatmap shows transcripts found to be significantly differentially expressed (columns, fold change $>1.5, \mathrm{BH}$-adjusted $\mathrm{p}$-value $<0.05$ ) in the patient samples (rows) across diverse stimulation conditions (LPS, L18MDP and $\alpha \mathrm{CD} 3 / \alpha \mathrm{CD} 28$ ) at 16 hours post stimulation. IL23A and IL10 expression are shown on the right as $\log 2$ fold change expression to the unstimulated PBMC (CTRL) median expression. (D, E) Networks of genes significantly up-regulated (D) or downregulated (E) by IL-10 signalling blockade (aIL-10R) in unstimulated (black), LPS stimulated (red), L18MDP stimulated (green) and $\alpha \mathrm{CD} 3 / \alpha \mathrm{CD} 28$ stimulated (blue) patient samples (fold change $>1.5$; node size and edge-thickness are proportional to fold change). 
bioRxiv preprint doi: https://doi.org/10.1101/719492; this version posted January 31, 2020. The copyright holder for this preprint (which was not certified by peer review) is the author/funder, who has granted bioRxiv a license to display the preprint in perpetuity. It is made available under aCC-BY-NC-ND 4.0 International license.

\section{Supplementary Figure 2}

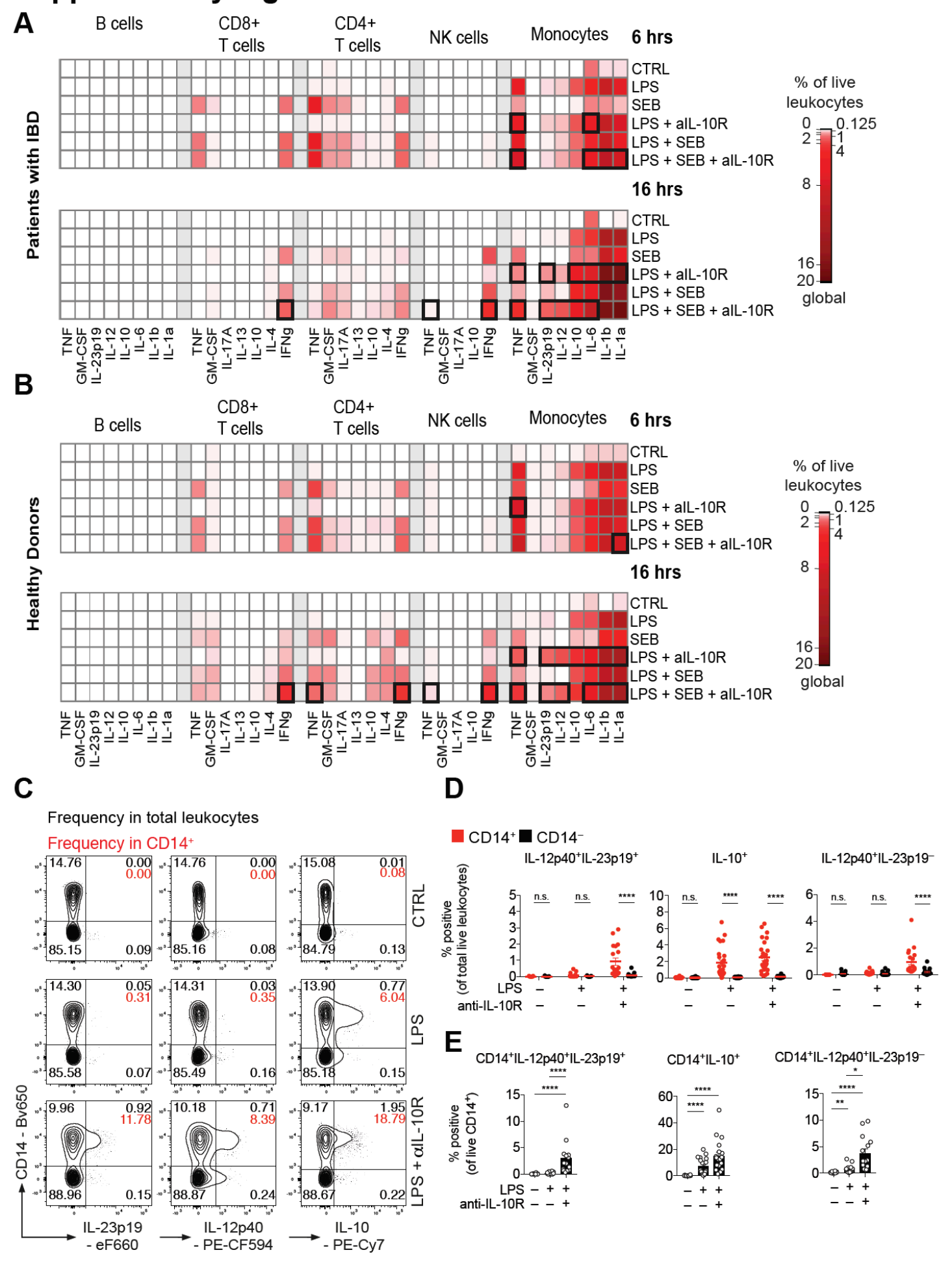


Supplementary Figure 2: (A and B) PBMC from patients with IBD (A; $n=7)$ or health individuals $(\mathrm{B} ; \mathrm{n}=10)$ were stimulated for 6 or 16 hours with combinations of LPS (200 $\mathrm{ng} / \mathrm{ml})$, SEB $(1 \mu \mathrm{g} / \mathrm{ml})$ and IL-10R blocking antibodies $(10 \mu \mathrm{g} / \mathrm{ml})$ with BFA present for the last $4 \mathrm{hrs}$ of culture. Cells were then surface stained to identify distinct leukocyte populations followed by intracellular cytokine staining. The frequency of cytokine producing cells for each population was assessed and presented as \% cytokine producing cells of total live leukocytes. Monocytes were identified as $\mathrm{CD} 14^{+} \mathrm{CD} 3^{-} \mathrm{CD} 19^{-} \mathrm{CD} 56^{-}, \mathrm{CD} 4^{+} \mathrm{T}$ cells as $\mathrm{CD} 3^{+} \mathrm{CD} 4^{+} \mathrm{CD} 8^{-}$ $\mathrm{CD} 14^{-} \mathrm{CD} 19^{-} \mathrm{CD} 56^{-}, \mathrm{CD}^{+} \mathrm{T}$ cells as $\mathrm{CD}^{+} \mathrm{CD}^{+} \mathrm{CD} 4^{-} \mathrm{CD} 14^{-} \mathrm{CD} 19^{-} \mathrm{CD} 56^{-} \mathrm{NK}$ cells as $\mathrm{CD}^{+} 6^{+} \mathrm{CD} 3^{-} \mathrm{CD} 14^{-} \mathrm{CD} 19^{-}$and $\mathrm{B}$ cells were identified as $\mathrm{CD}^{+} 9^{+} \mathrm{CD}^{-} \mathrm{CD} 14^{-} \mathrm{CD} 56^{-}$(Mean; bold squares indicate $\mathrm{p}<0.05$; Mann-Whitney test). (C) Contour plot presentation of IL-23p19, IL-12p40- and IL-10-producing live leukocytes and CD14 surface expression measured at 16 hours post stimulation in HD PBMC. (D) Summary of frequencies of IL-12p40 IL-23p19 ${ }^{+}$, IL$10^{+}$and IL-12p40 ${ }^{+} \mathrm{IL}-23 \mathrm{p} 19^{-} \mathrm{CD} 14^{+}$and CD14 $4^{-}$cells in HD total live leukocytes $(\mathrm{n}=26)$. Mean +/- SEM; Mann-Whitney test. (E) Summary of frequencies of IL-12p40 IL-23p19 ${ }^{+}$, IL-10 and IL-12p $40^{+}$IL-23p19 $9^{-}$of HD CD $14^{+}$cells $(\mathrm{n}=26)$. Mean +/- SEM; Mann-Whitney test. 
bioRxiv preprint doi: https://doi.org/10.1101/719492; this version posted January 31, 2020. The copyright holder for this preprint (which was not certified by peer review) is the author/funder, who has granted bioRxiv a license to display the preprint in perpetuity. It is made available under aCC-BY-NC-ND 4.0 International license.

\section{Supplementary Figure 3}

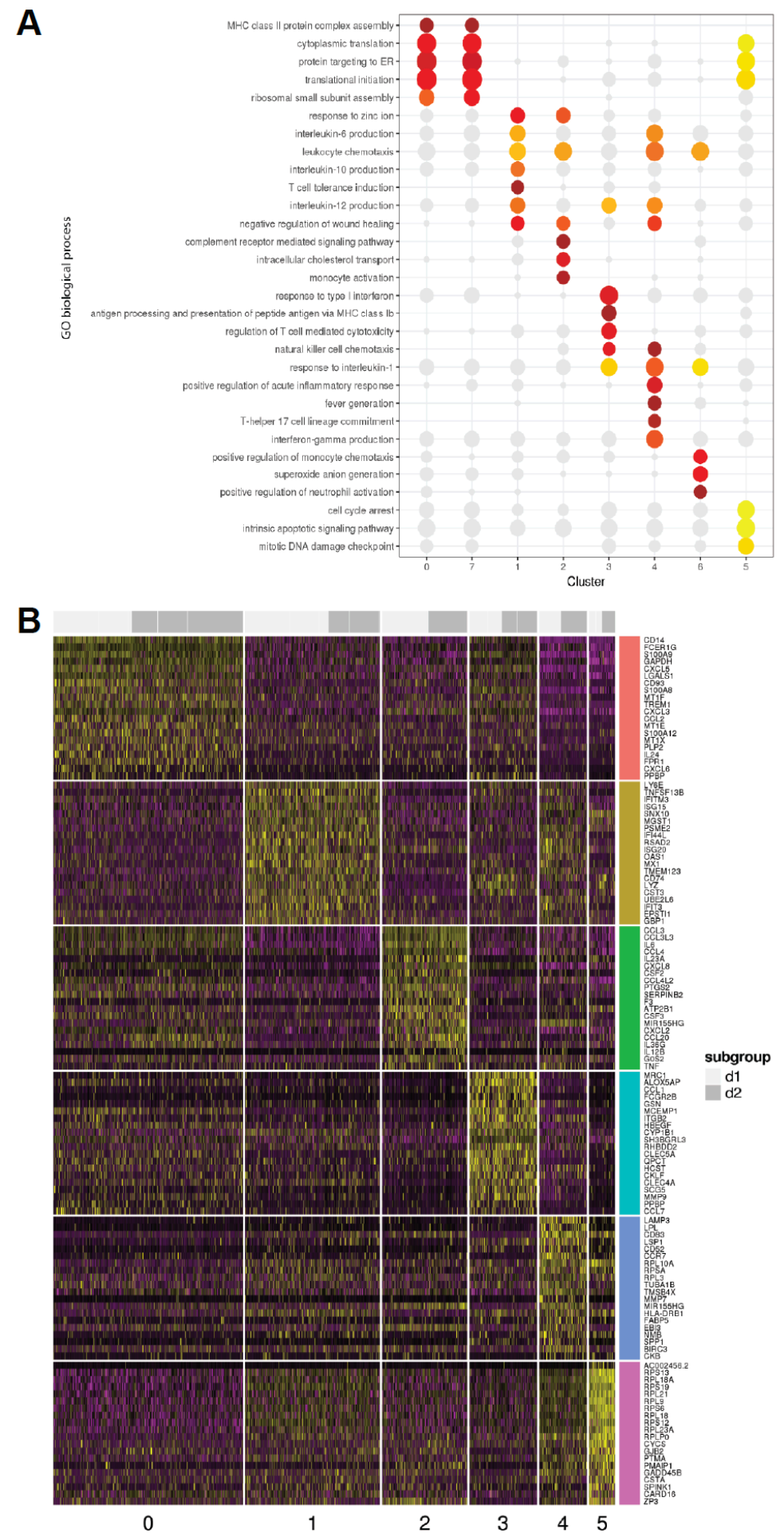


Supplementary Figure 3: Single cell genomics identifies transcriptionally distinct monocyte clusters following combined LPS + anti-IL-10R stimulation. (A) Selected overrepresented GO biological process gene sets of the 8 identified monocyte clusters across stimulation conditions (Unstimulated, LPS-stimulated and LPS + anti-IL-10R-stimulated). (B) Heatmap of cluster marker genes for cell-cycle corrected analysis of the LPS + anti-IL-10R condition alone (donors 1 and 2). Cluster 1 corresponds to cluster 3 in the aligned analysis (Interferon-induced monocytes), cluster 2 to cluster 4 in the aligned analysis (IL-23 ${ }^{+}$ inflammatory monocytes) and cluster 3 to cluster 6 in the aligned analysis $\left(\mathrm{MRC1}^{+}\right.$ microbicidial monocyte subpopulations). 
bioRxiv preprint doi: https://doi.org/10.1101/719492; this version posted January 31, 2020. The copyright holder for this preprint (which was not certified by peer review) is the author/funder, who has granted bioRxiv a license to display the preprint in perpetuity. It is made available under aCC-BY-NC-ND 4.0 International license.

\section{Supplementary Figure 4}

A

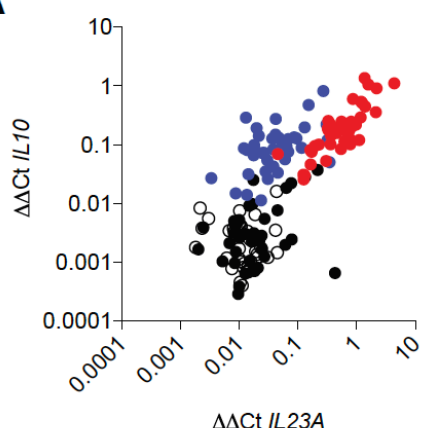

LPS + anti-IL-10R Spearman $r=0.8385$ $P$ value $<0.0001$

- LPS Spearman $r=0.4452$

$P$ value $=0.0040$

- anti-IL-10R

Spearman $r=0.2280$

$P$ value $=0.1572$

O CTRL

Spearman $r=-0.2046$

$P$ value $=0.2245$
B

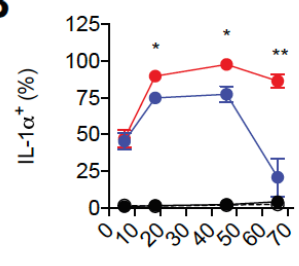

Hours

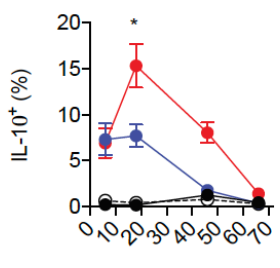

Hours

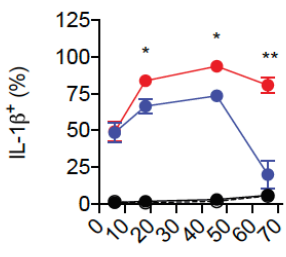

Hours

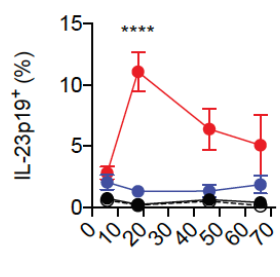

Hours
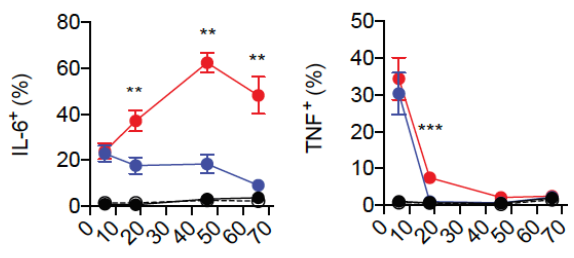

$\ominus-$ CTRL

- anti-IL-10R

- - LPS

- LPS + anti-IL-10R
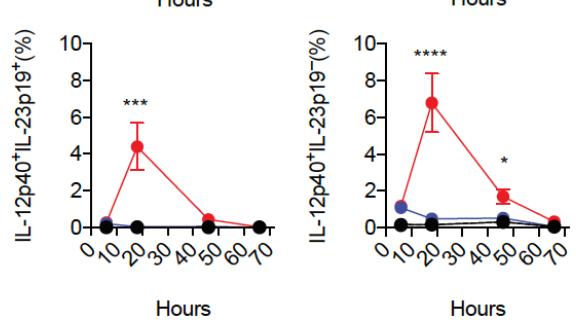
Supplementary Figure 4: $I L 23 A$ and $I L 10$ gene expression positively correlate under settings of LPS stimulation and IL-10 signalling blockade and monocytes produce cytokines with distinct kinetics. (A) RT-qPCR based $\Delta \Delta \mathrm{Ct}$ correlation analysis of ILIO and IL23A gene expression in unstimulated, anti-IL-10R $(10 \mu \mathrm{g} / \mathrm{ml})$, LPS $(200 \mathrm{ng} / \mathrm{ml})$, and combined LPS and anti-IL-10R-stimulated PBMC (n=40). (B) PBMC were stimulated for up to 66 hours with combinations of LPS and anti-IL-10R. The frequencies of cytokine producing live $\mathrm{CD} 14^{+}$cells were assessed by surface and intracellular staining at different time points, as indicated ( $\mathrm{n}=4-10$, Mean +/- SEM; Kruskal-Wallis test; BH-adjusted p-values). 
bioRxiv preprint doi: https://doi.org/10.1101/719492; this version posted January 31, 2020. The copyright holder for this preprint (which was not certified by peer review) is the author/funder, who has granted bioRxiv a license to display the preprint in perpetuity. It is made available under aCC-BY-NC-ND 4.0 International license.

\section{Supplementary Figure 5}

A

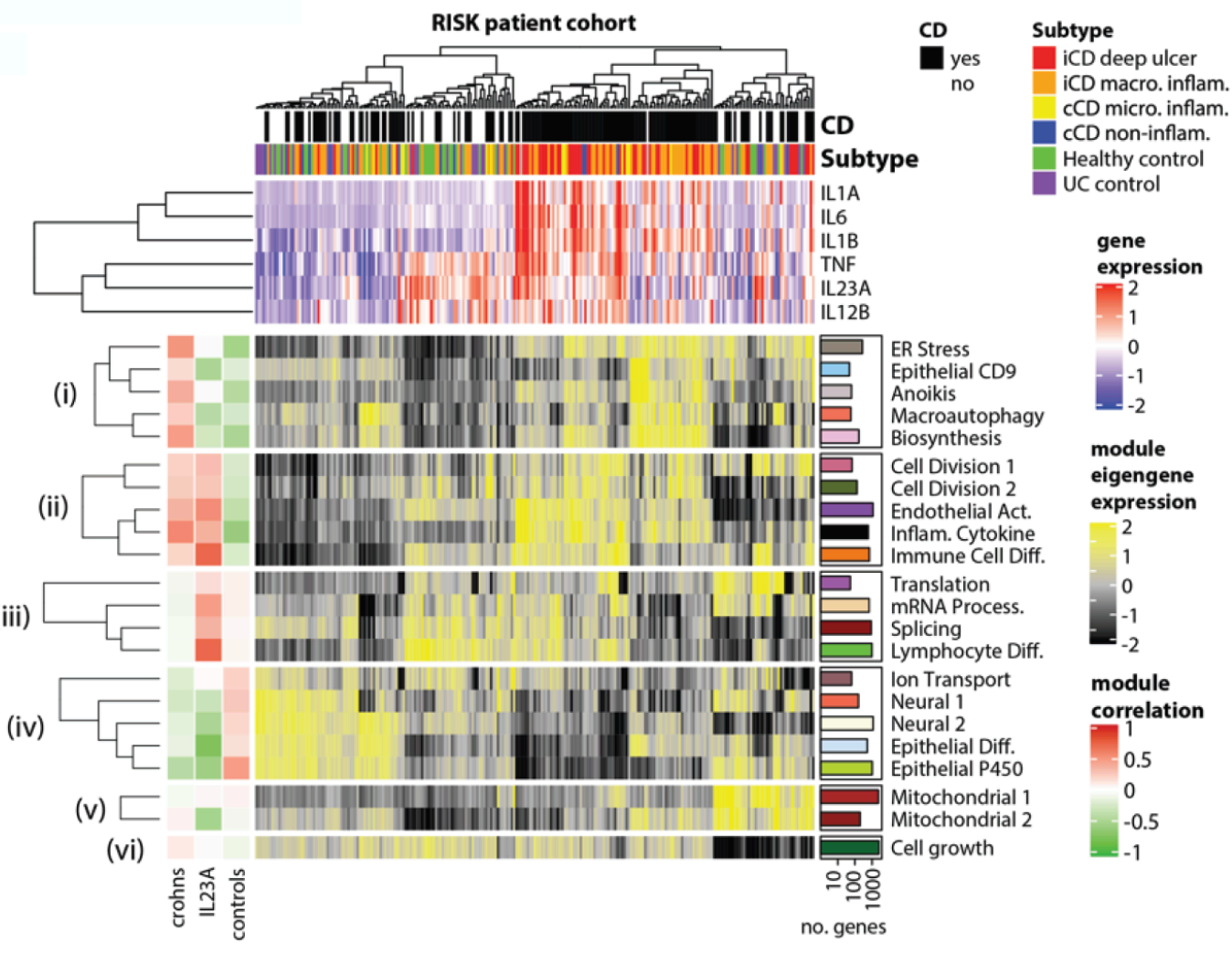

B

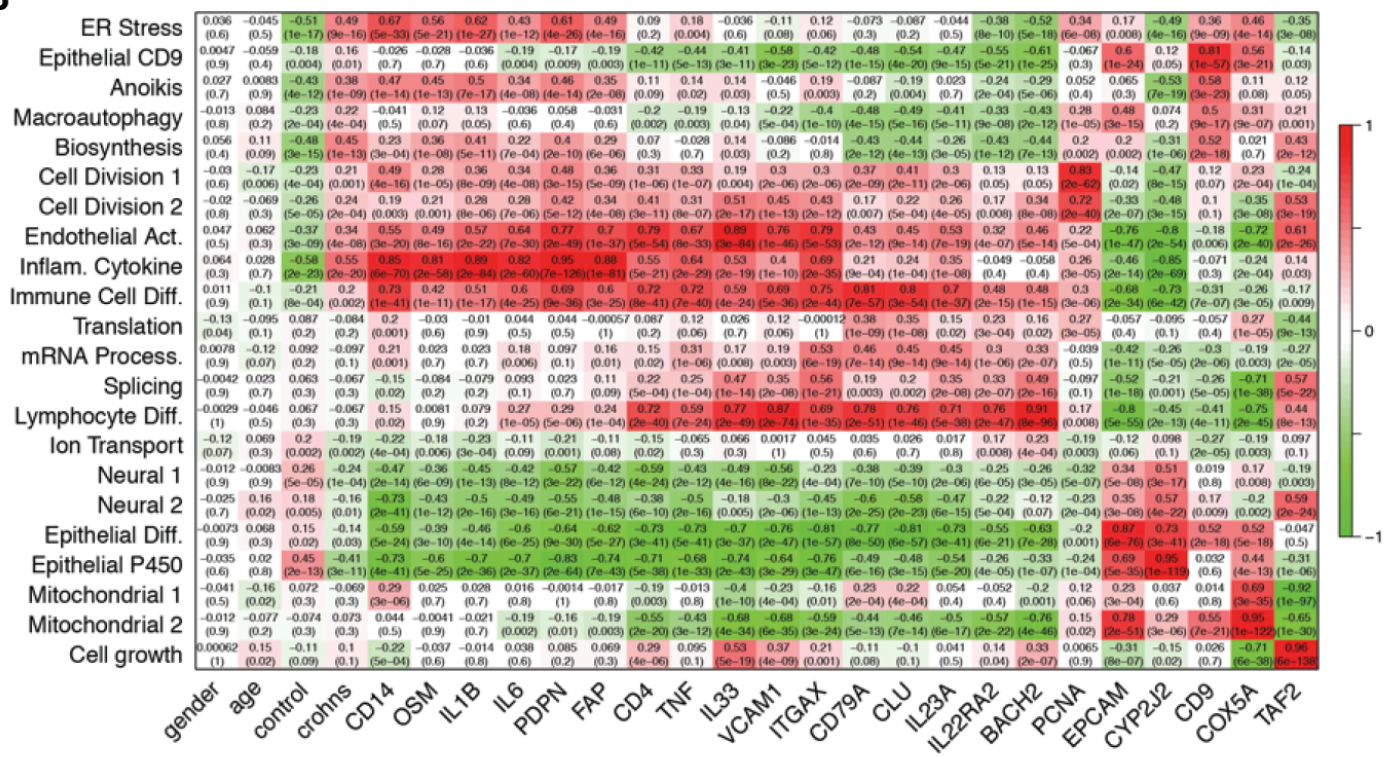




\section{Supplementary Figure 5: Identification of modules of co-expressed genes in patient}

biopsies from the paediatric RISK cohort. (A) The main heatmap shows expression of the eigen-genes of the $n=22$ identified modules of genes. Patients (columns) are hierarchically clustered by expression of the module eigen-genes. The heat map is annotated with (i) patient diagnosis and disease subtype (top panels), (ii) expression of key cytokines (upper heatmap), (iii) correlation of the eigen-genes with diagnosis of Crohn's disease, IL23A expression and control status (left panel) and (iv) the numbers of genes within each of the modules (right panel). Modules were named according to enrichments for gene ontology and cell type genesets (Supplementary Table 4). (B) The heatmap shows the correlation of the RISK WGCNA modules (y-axis) with genes and traits of interest (x-axis). 
bioRxiv preprint doi: https://doi.org/10.1101/719492; this version posted January 31, 2020. The copyright holder for this preprint (which was not certified by peer review) is the author/funder, who has granted bioRxiv a license to display the preprint in perpetuity. It is made available under aCC-BY-NC-ND 4.0 International license.

\section{Supplementary Figure 6}

A

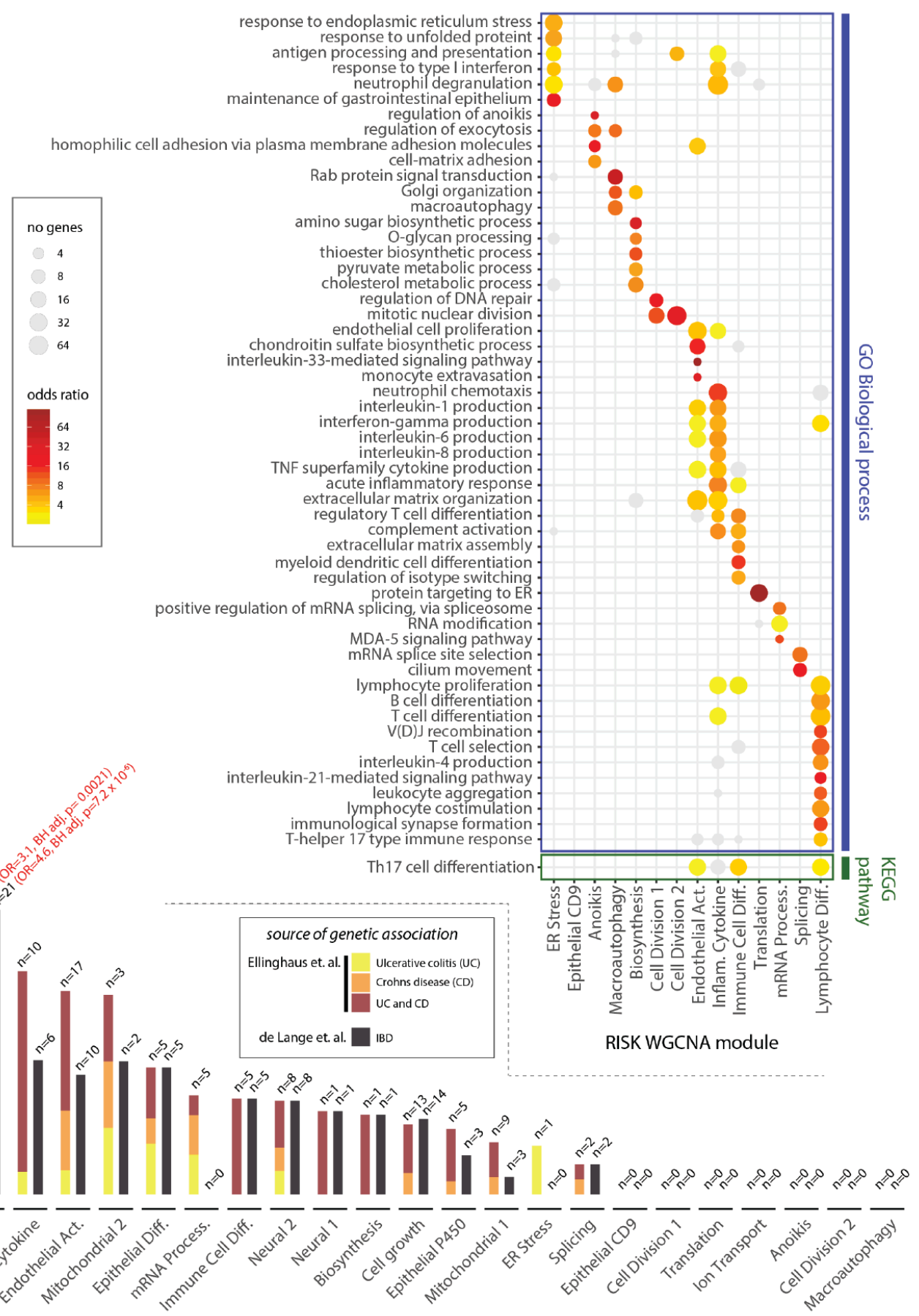

RISK WGCNA module 
Supplementary Figure 6: Characterisation of the RISK WGCNA modules. (A) The dotplot shows the enrichment of selected biological process gene ontology categories and KEGG pathways in the WGCNA modules that were correlated with diagnosis of Crohn's disease and/or IL23A expression (one-sided Fisher tests, BH-adjusted $\mathrm{p}<0.05$, p-values adjusted separately for GO categories and KEGG pathways). (B) The frequency (y axis) of IBD GWASassociated genes in the different RISK WGCNA modules ( $\mathrm{x}$ axis). Genetically associated genes were sourced from Ellinghaus et. al. ${ }^{51}$ or de Lange et. $a l .{ }^{5}$ (see methods). BH-adjusted p-values and odds ratios are given for significant enrichments (red text). 
bioRxiv preprint doi: https://doi.org/10.1101/719492; this version posted January 31, 2020. The copyright holder for this preprint (which was not certified by peer review) is the author/funder, who has granted bioRxiv a license to display the preprint in perpetuity. It is made available under aCC-BY-NC-ND 4.0 International license.

\section{Supplementary Figure 7}

A
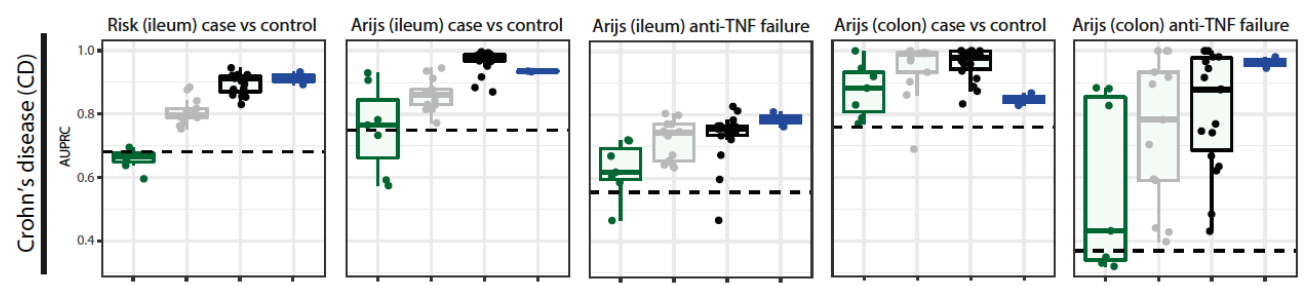

B
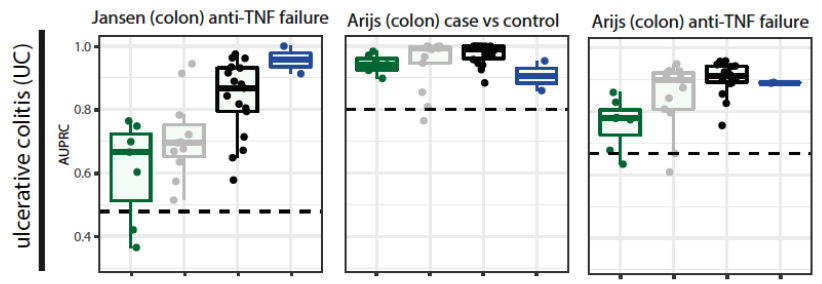

\section{group:}

审 correlated with inflammatory cytokine module

correlated with both modules

审 correlated with lymphocyte diff. module

宇 control genes
C

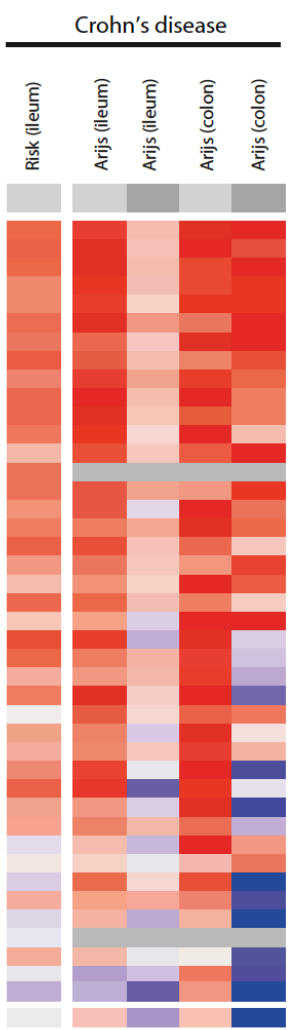

AUPRC
-1
-1
-0.8
-0.6
-0.4

\section{group:}

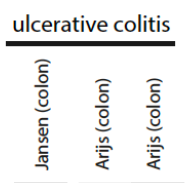

prediction

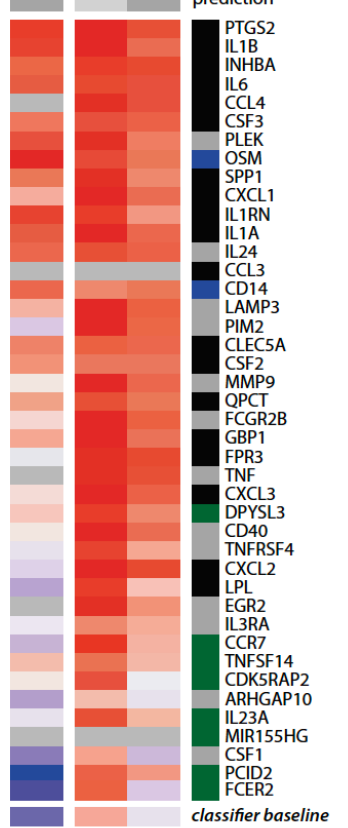

control genes

correlated with inflammatory cytokine module

correlated with both modules

correlated with lymphocyte diff. module
D

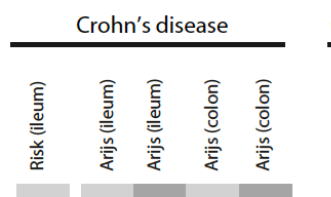

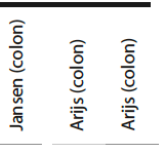

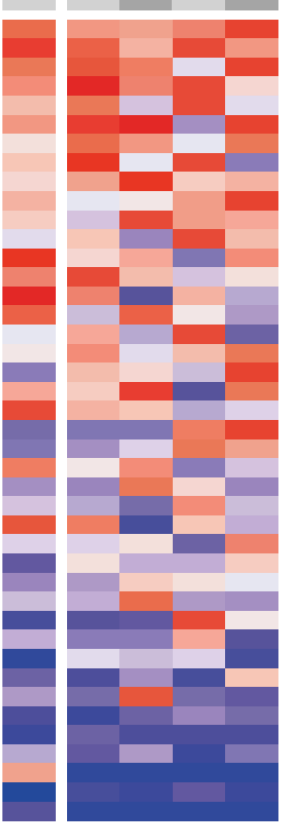

prediction
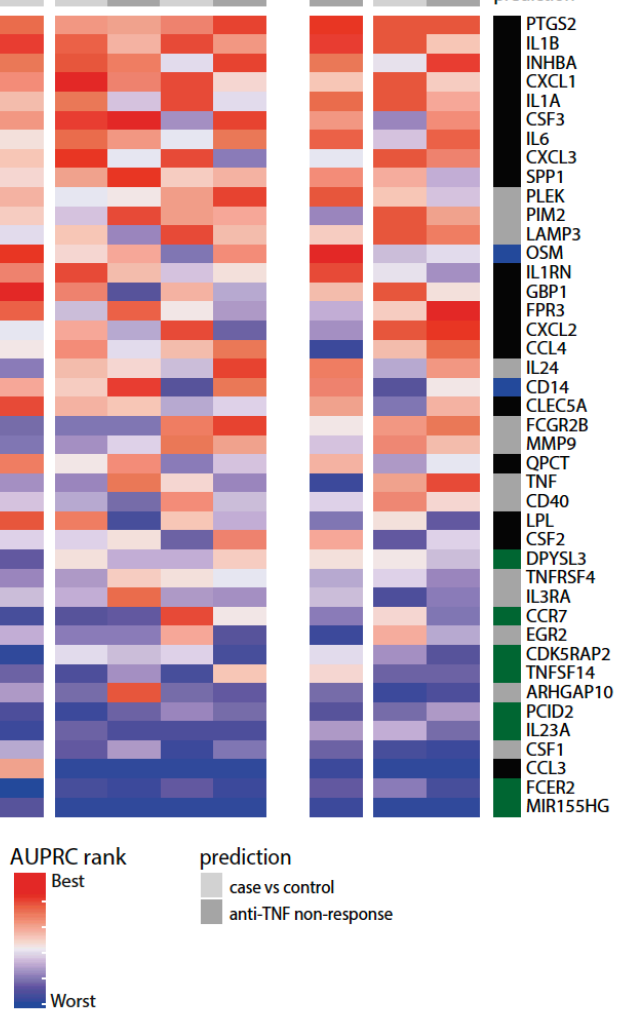


\section{Supplementary Figure 7: Ability of inflammatory monocyte signature genes to predict} inflammatory bowel disease and non-response to anti-TNF therapy in three patient cohorts. Comparison of the ability of the identified subsets of monocyte genes (see Figure 4) to predict diagnosis of inflammatory bowel disease and TNF non-response in the RISK (GSE57945), Janssen (GSE12251) and Arijs (GSE16879) cohorts. (A) Predictions in Crohn's disease with data from the RISK and Arijs cohorts. (B) Predictions in ulcerative colitis with data from the Janssen and Arijs cohorts. The panels from the RISK and Janssen cohorts in (A) and (B) are reproduced from Figure 4. The dashed lines indicate random classifier performance. (C) The heatmap shows the AUPRC values of the individual genes for the predictions shown in (A) and (B). (D) The heatmap show the ranks of the predictions for the individual genes. Genes in panels (C) and (D) are ordered by the mean of the AUPRC and AUPRC rank respectively. AUPRC: area under precision recall curve. 


\section{Supplementary Figure 8}

\section{A}

Fold change to LPS/LPS + alL-10R

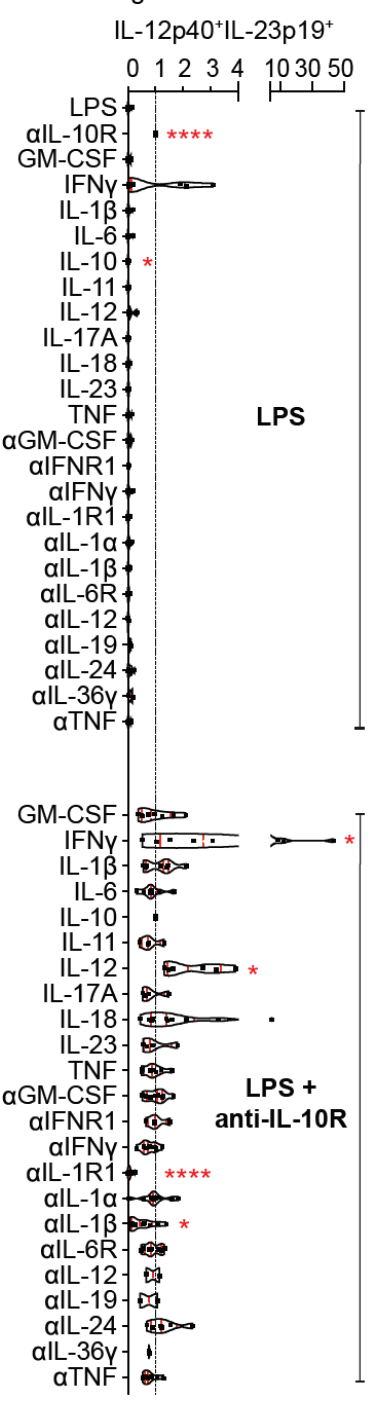

B

E
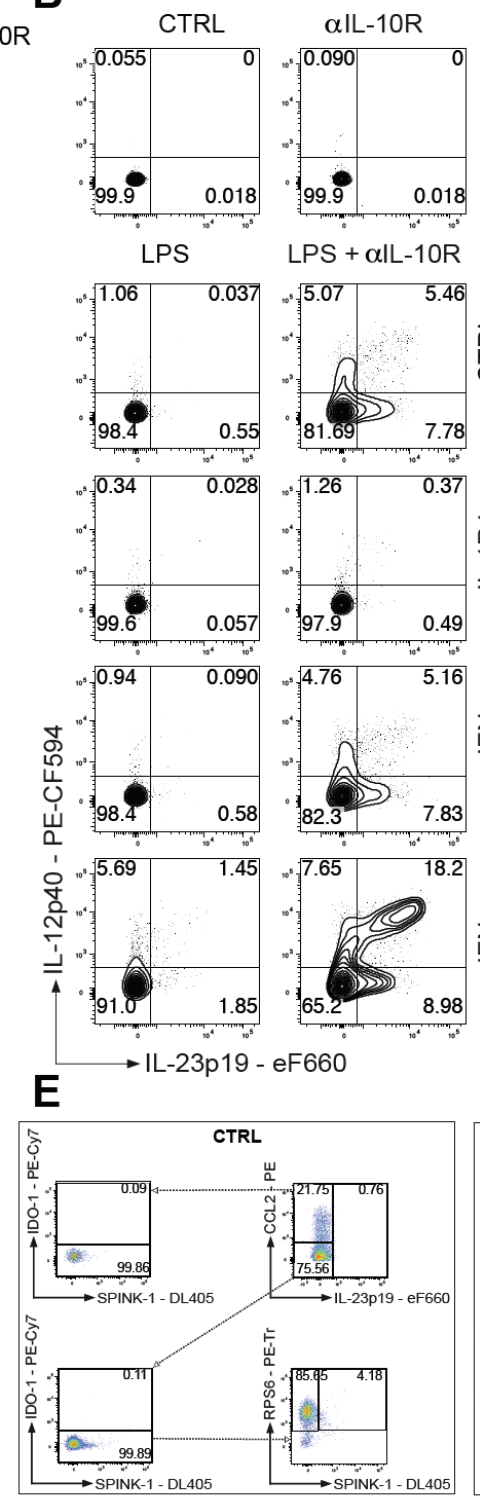

LPS $+\alpha$ LL-10R
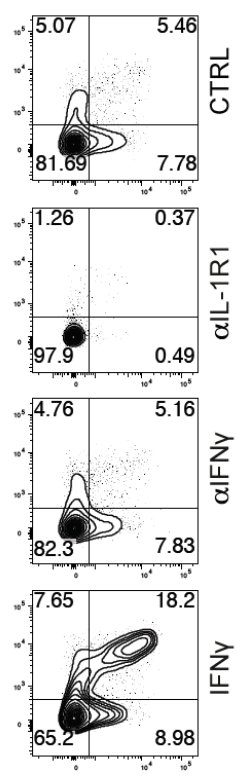

C

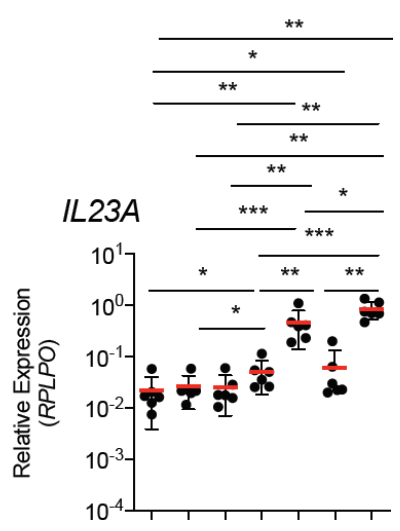

alL-10R - $\quad-\quad+++$

LPS - + + + + +

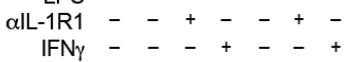

D
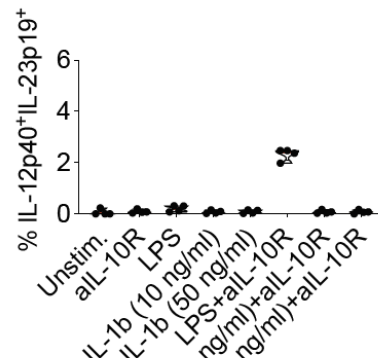

तiviv

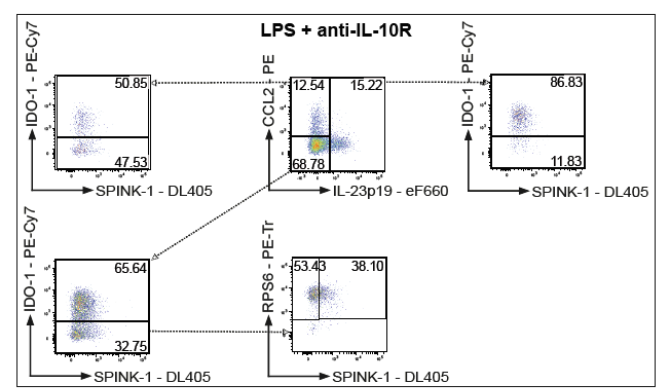




\section{Supplementary Figure 8: IL-1 $\alpha$ and IL-1 $\beta$ signalling are essential for inducing monocyte}

IL-23 production. PBMC from patients with IBD ( $n>4)$ were stimulated for 16 hours with combinations of LPS and $\alpha \mathrm{IL}-10 \mathrm{R}$ in the presence of indicated exogenous human recombinant cytokine, cytokine receptor blockade or cytokine blockade. (A) The frequencies of cytokine producing live $\mathrm{CD} 14^{+}$cells were assessed by intracellular staining. Summary of IL-12p40 IL$23 \mathrm{p} 19^{+}$cell frequencies measured under diverse stimulation conditions; Wilcoxon test; 95\% CI). (B) Representative dot plot showing intracellular IL-12p40 and IL-23p19 in CD14 monocytes of one healthy donor. (C) RT-qPCR analysis of healthy donor PBMC stimulated with combinations of LPS, anti-IL-10R, anti-IL-1R1 and IFN- $\gamma$ for 16 hours. (D) Frequencies of IL-12p $40^{+}$IL-23p $19^{+}$live CD $14^{+}$monocytes after 16 hours stimulation with combinations of LPS (200 ng/ml), anti-IL-10R $(10 \mu \mathrm{g} / \mathrm{ml})$ and IL-1 $\beta$ (10 and $50 \mathrm{ng} / \mathrm{ml})$. (E) Dot plot presentation of one representative experiment showing live $\mathrm{CD} 14^{+}$-gated monocytes and subgating strategies based on the expression of IL-23p19, CCL2, IDO-1 RPS6 and SPINK-1 in non-stimulated, LPS-stimulated and combined LPS and anti-IL-10R stimulated PBMC. 
bioRxiv preprint doi: https://doi.org/10.1101/719492; this version posted January 31, 2020. The copyright holder for this preprint (which was not certified by peer review) is the author/funder, who has granted bioRxiv a license to display the preprint in perpetuity. It is made available under aCC-BY-NC-ND 4.0 International license.

\section{Supplementary Figure 9}

\section{A}

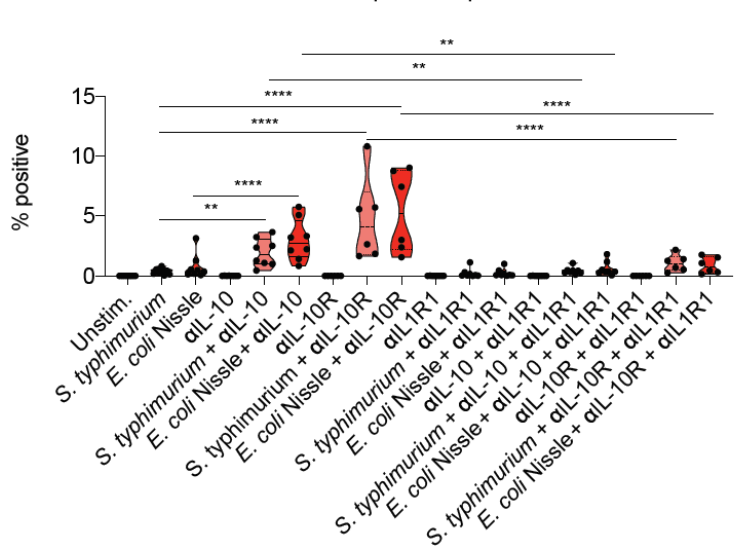

B
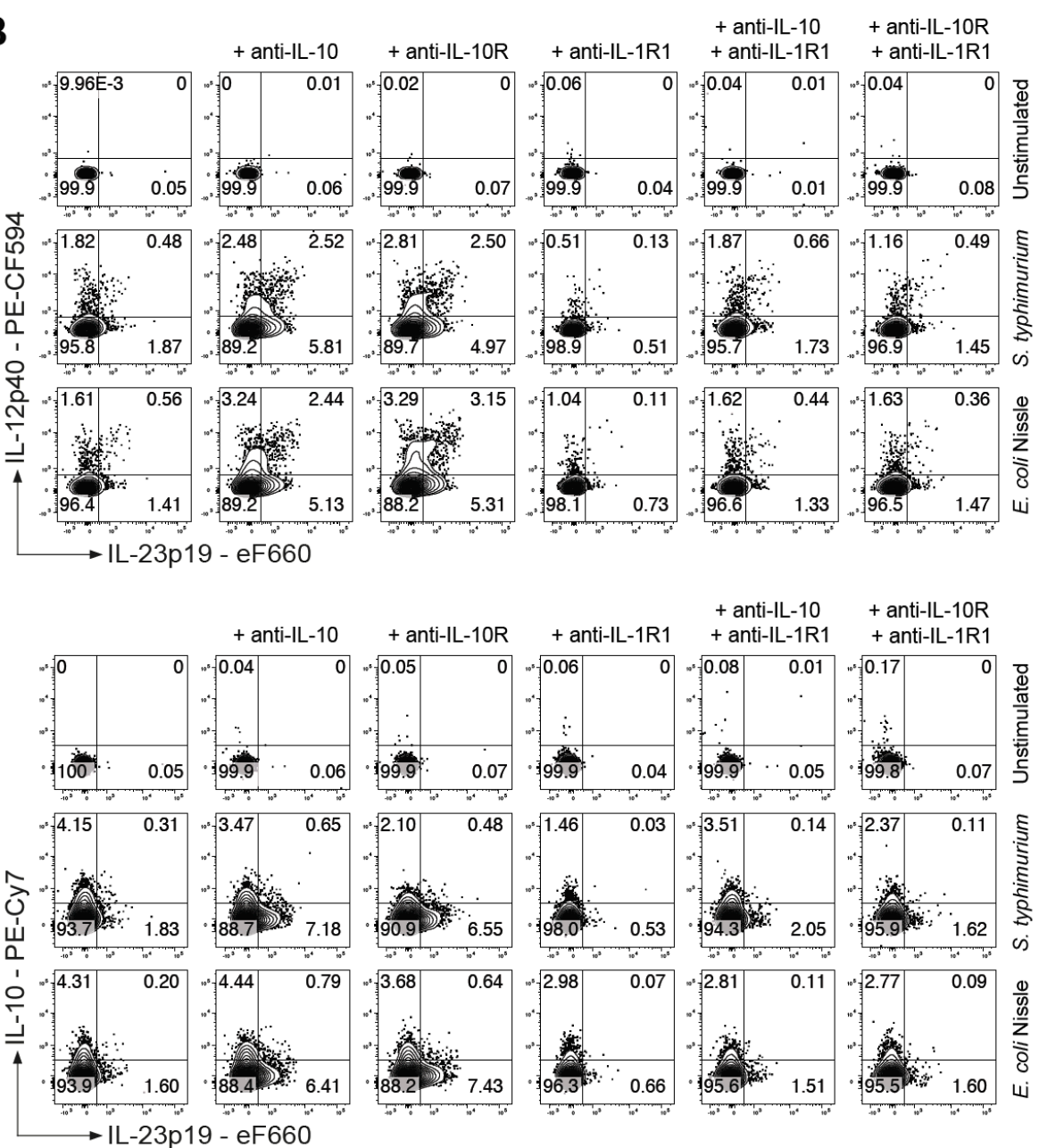
Supplementary Figure 9: Monocyte IL-23 production induced by uptake of whole bacteria is dependent on IL-1R1 signalling. (A) Summary of frequencies of IL-12p40 IL$23 \mathrm{p} 19^{+}$live $\mathrm{CD} 14^{+}$cells as assessed by intracellular staining measured in indicated conditions at 16 hours following stimulation $(\mathrm{n}=8$, Mean +/- SEM; Kruskal-Wallis test; FDR-adjusted BH-adjusted p-values). (B) Representative dot plots showing intracellular IL-12p40, IL-23p19 and IL-10 in live CD14 $4^{+}$monocytes of one healthy donor. 
bioRxiv preprint doi: https://doi.org/10.1101/719492; this version posted January 31, 2020. The copyright holder for this preprint (which was not certified by peer review) is the author/funder, who has granted bioRxiv a license to display the preprint in perpetuity. It is made available under aCC-BY-NC-ND 4.0 International license.

\section{Graphical Abstract}

Healthy/non-active CD

Lamina propria

MALT

Inflammation

GO-pathways:
Lymphocyte Differentiation mRNA Processing Translation
Active CD

Deep Ulcers/

Macroscopic Inflammation
Epithelial Differentiation
Neural Signal

Ion Transport
ER Stress

Macroautophagy
Inflammatory Cytokine Immune Cell Differentiation

Endothelial Activation Cell Division

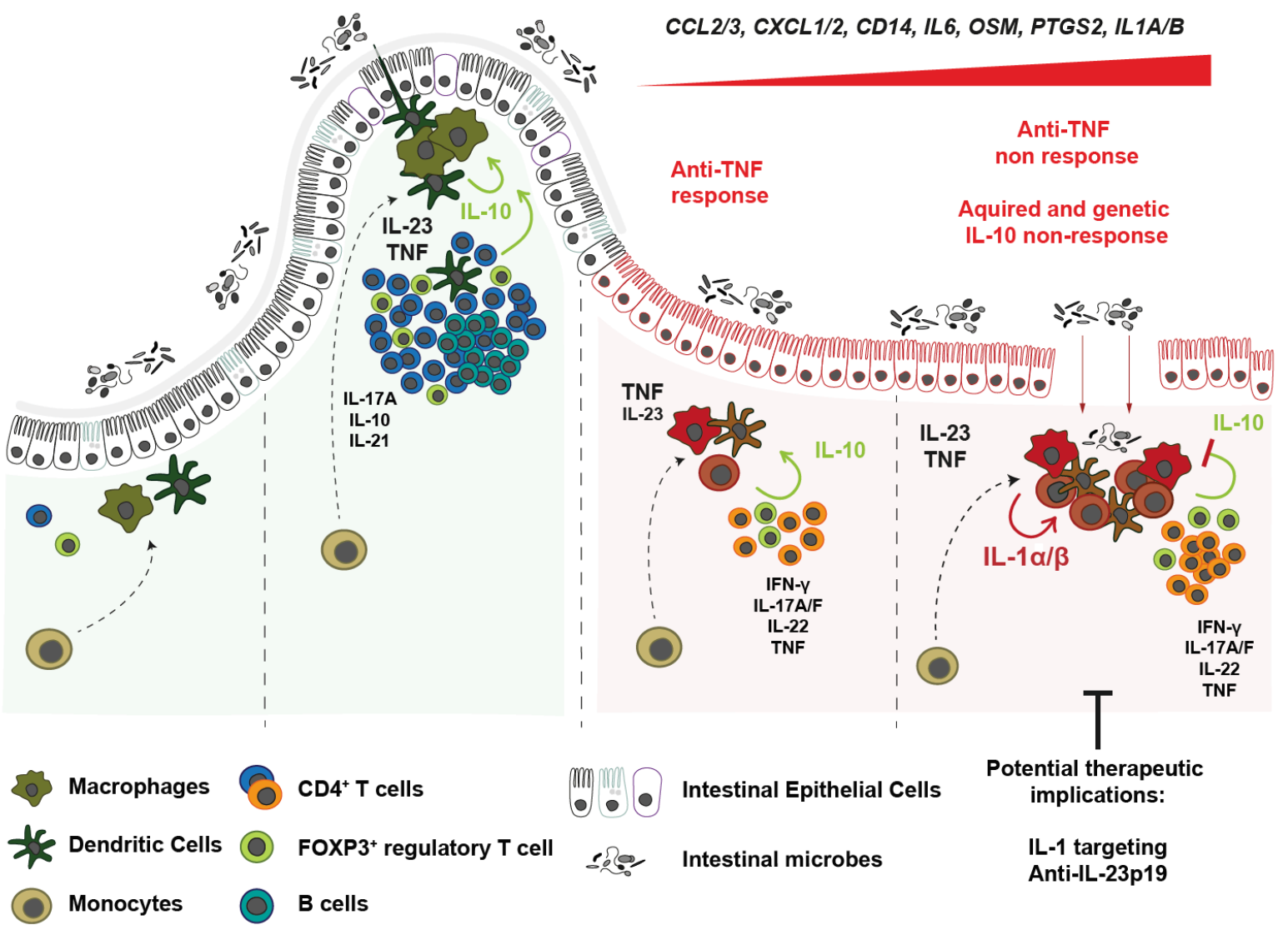

